\title{
TMI-2 ANALYSIS USING SCDAP/RELAP5/MOD3.1
}

\author{
J. R. Hohorst \\ s. T. Polkinghorne \\ I. J. Siefken \\ C. M. Allison \\ C. A. Dobbe
}

Published November 1994

\author{
Idaho National Engineering Laboratory \\ Lockheed Idaho Technologies Company \\ Idaho Falls, Idaho 83415
}

\section{Work supported by the \\ U.S. Nuclear Regulatory Commission Accident Evaluation Branch \\ under DOE Contract No. DE-ACO7-94ID13223}

This report was prepared as an account of work sponsored by an agency of the United States Government. Neither the United States Government nor any agency thereof, nor any of their employees, makes any warranty, express or implied, or assumes any legal liability or responsibility for the accuracy, completeness, or usefulness of any information, apparatus, product, or process disclosed, or represents that its use would not infringe privately owned rights. Reference herein to any specific commercial product, process, or service by trade name, trademark, manufacturer, or otherwise does not necessarily constitute or imply its endorsement, recommendation, or favoring by the United States Government or any agency thereof. The views and opinions of authors expressed herein do not necessarily state or reflect those of the United States Government or any agency thereof. 



\section{DISCLAIMER}

Portions of this document may be illegible in electronic image products. Images are produced from the best available original document. 


\section{CONTENTS}

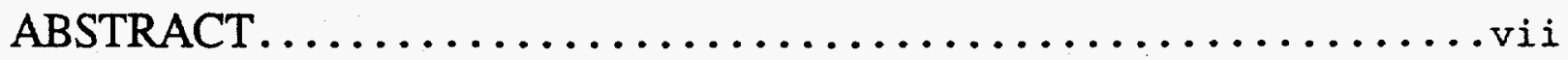

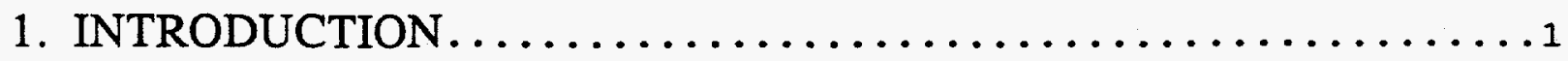

2. SCDAP/RELAP5 TMI-2 MODEL.....................

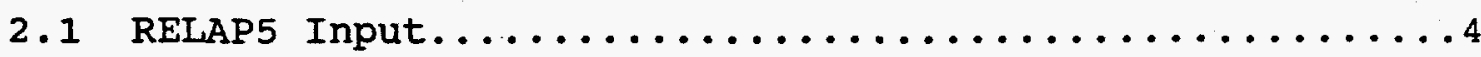

2.1 .1 Reactor vessel.....................

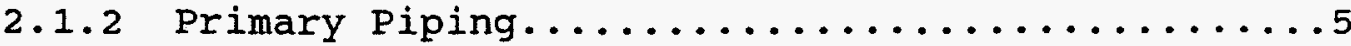

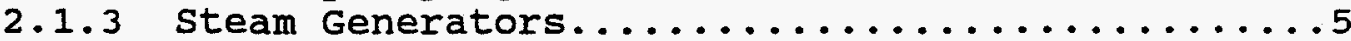

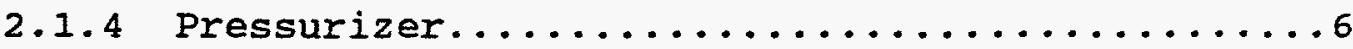

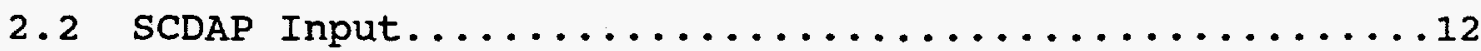

2.3 Couple Input........................

2.4 Initial Conditions.....................

2.5 Boundary Conditions.......................

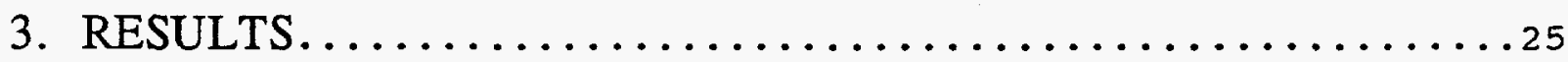

3.1 Base Case Best-estimate Calculation............25

3.2 Influence of Makeup Flow..................

3.3 Influence of Injections during $2 B$ Pump Transient....42

4. CONCLUSIONS .......................... 45

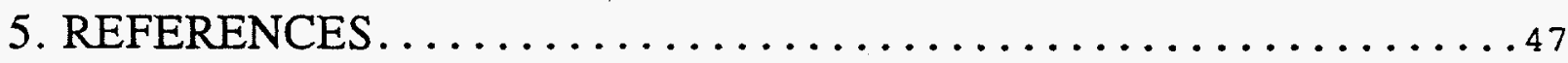




\section{FIGURES}

1. RELAP5 nodalization of the reactor vessel and core.......5

2. RELAP5 nodalization of primary coolant loop A...........7

3. RELAP5 nodalization of steam generator A...............

4. RELAP5 nodalization of the pressurizer...............

5. Cross-section of core showing fuel assembly grouping and

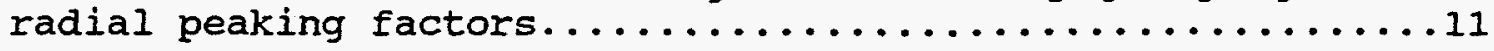

6. COUPLE finite element mesh used to model the lower head of the reactor vessel.........................16

7. Makeup flow used for the best-estimate calculation.......20

8. Calculated steam generator A coolant level compared to

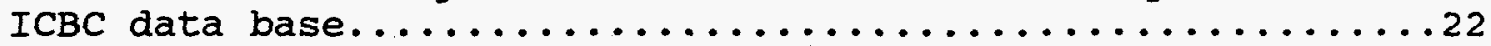

9. Calculated steam generator B coolant level compared to

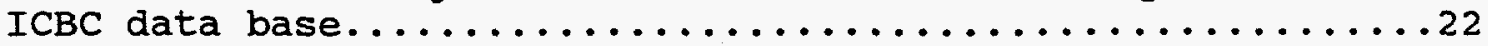

10. Calculated steam generator A pressure compared to

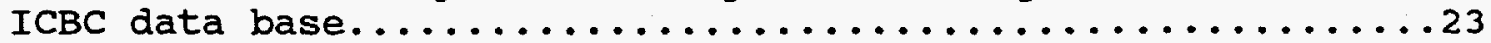

11. Calculated steam generator B pressure compared to

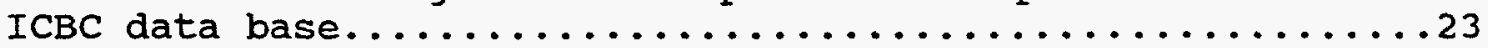

12. Calculated letdown flow rates compared to ICBC data base...24

13. Reactor power versus time curve used for TMI-2 calculation..24

14. Makeup flow rate used for the best-estimate calculation....26

15. Comparison of letdown, makeup and PORV flow rates........26

16. Calculated best-estimate and measured pressures.........27

17. Predicted best-estimate collapsed liquid level..........27

18. Predicted best-estimate maximum core temperature........28

19. Predicted best-estimate integral hydrogen production.......28

20. Hypothesized TMI-2 core damage state prior to the

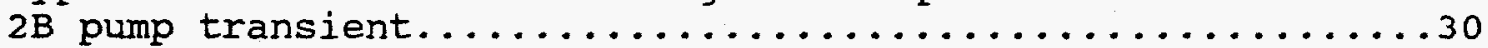

21. Predicted TMI-2 core damage state prior to the

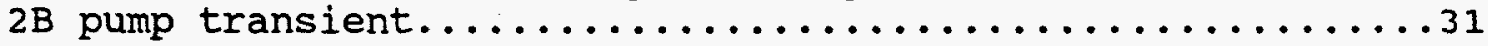


22. Hypothesized end-state of the TMI-2 core...............33

23. Predicted end-state of the TMI-2 core................. 34

24. Predicted radial temperature profile at the $2.19 \mathrm{~m}$

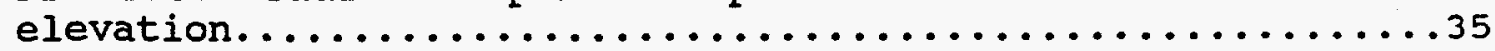

25. Predicted radial temperature profile at the $2.56 \mathrm{~m}$

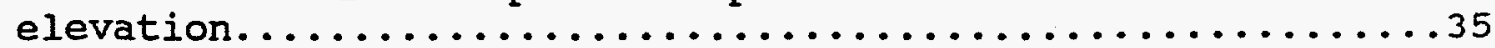

26. Calculated system pressure from sensitivity study .......40

27. Calculated collapsed liquid level from sensitivity study....40

28. Calculated maximum core temperature from sensitivity study..................................41

29. Integral hydrogen production from sensitivity study $\ldots \ldots \ldots 41$

30. Makeup, letdown, and calculated PORV flows from the best-estimate case............................44

31. Calculated pressure responses from $2 B$ pump flow sensitivity study............................ 44

\section{TABLES}

1. TMI-2 axial power peaking factors..................

2. Total fuel assemblies, fuel rods, and control rods

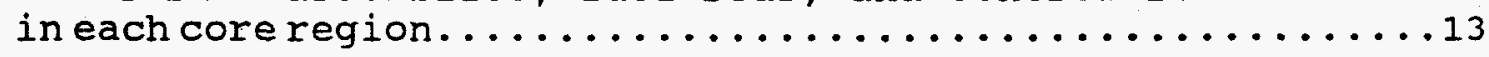

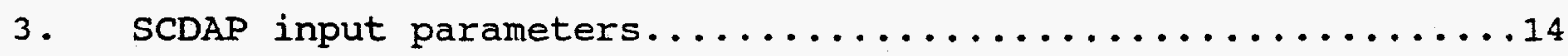

4. TMI-2 initial conditions at turbine trip...............

5. Steamgenerator initial conditions.................

6. Summary of variation in makeup flow ...................

7. Core damage prior to the $2 B$ pump transient.............38

8. Core damage after the 2 B pump transient.............

9. Core damage after sustained HPI injection.................

10. 2B-pump sensitivity study ..................... 43 
… 


\begin{abstract}
SCDAP/RELAP5/MOD3.1, an integrated thermal hydraulic analysis code developed primarily to simulate severe accidents in nuclear power plants, was used to predict the progression of core damage during the TMI-2 accident. The version of the code used for the TMI-2 analysis described in this paper includes models to predict core heatup, core geometry changes, and the relocation of molten core debris to the lower plenum of the reactor vessel. This paper describes the TMI-2 input model, initial conditions, boundary conditions, and the results from the best-estimate simulation of Phases 1 to 4 of the TMI-2 accident as well as the results from several sensitivity calculations.
\end{abstract}

vii 


\title{
TMI-2 ANALYSIS USING SCDAP/RELAP5/MOD3.1
}

\author{
J. K. Hohorst \\ S. T. Polkinghorne \\ I. J. Siefken \\ C. M. Allison \\ C. A. Dobbe
}

Idaho National Engineering Laboratory

P. O. Box 1625

Idaho Falls, Idaho 83415

\begin{abstract}
Work supported by the U.S. Nuclear Regulatory Commission, Accident Evaluation Branch, under

DOE Contract No. DE-AC07-94ID13223
\end{abstract}

\section{INTRODUCTION}

The SCDAP/RELAP5/MOD3.1 computer code, was used to predict the progression of core damage during the TMI-2 accident. SCDAP/RELAP5/MOD3.1 is an integrated thermal-hydraulic analysis code developed primarily to simulate severe accidents in nuclear power plants. It includes models to predict core heatup, core geometry changes, and the relocation of molten core debris to the lower plenum of the reactor vessel. This report describes the TMI-2 input model, initial conditions, boundary conditions, and results from the best-estimate simulation of Phases 1 through 4 of the TMI-2 accident as well as the results from several sensitivity calculations. The primary objectives of this analysis were to (a) calculate all of the relevant phenomena believed to have occurred during the TMI-2 accident, (b) exercise and assess various core damage models and options, and (c) determine if the most recent version of SCDAP/RELAP5 is better able to predict the progression of core damage during the TMI-2 accident than previous code versions. This work represents an 
ongoing effort to simulate an actual severe accident using a state-of-the-art severe accident analysis code.

All major components of the TMI-2 primary system were modeled using the SCDAP/RELAP5/MOD3.1 code package. The RELAP5 module was used to simulate the thermal-hydraulics of the reactor vessel, primary coolant loops, steam generators, and pressurizer. steam generator secondary side coolant levels, pressures, and feedwater temperatures, and primary side makeup and letdown flow rates were supplied as boundary conditions. The SCDAP module was used to simulate the reactor core, which was divided into five radial regions by grouping similarly powered fuel assemblies together. The COUPLE module was used to simulate the reactor vessel lower head and the debris that slumps into the lower head during the accident.

The TMI-2 accident is generally divided into four distinct phases for analysis purposes. ${ }^{3}$ Phase 1 (0-100 min) is a smallbreak loss-of-coolant accident (LOCA) through the stuck-open pilot-operated relief valve (PORV). One or more reactor coolant system (RCS) pumps operated continuously during Phase 1 of the accident, thereby providing adequate core cooling. Phase 2 (100$174 \mathrm{~min})$ is a continuation of the small break LOCA without the RCS pumps. Core uncovery, heatup, and initial melting occurred during Phase 2. Phase 3 (174-200 min) begins with a restart of reactor coolant pump 2B. Approximately $30 \mathrm{~m}^{3}$ of coolant was injected into the reactor vessel in less than one minute, cooling the peripheral fuel assemblies and forming an upper core debris bed with significant zircaloy oxidation. Heatup of the degraded core region, with the formation and growth of a pool of molten material, continued during Phase 3. Phase 4 (200-300 min) begins with the initiation of high-pressure injection (HPI). The central region of the partially molten core material was not coolable by HPI even though the water level reached the level of the hot legs by $207 \mathrm{~min}$. Between 224 and $226 \mathrm{~min}$, the crust encasing and supporting the molten core region is believed to 
have failed, allowing molten material to relocate to the lower plenum.

The approach taken for this analysis was as follows: first, the influence of large thermal-hydraulic uncertainties on the state of the core during critical phases of the accident was established, and second, a best estimate calculation was performed using modeling options established during the extensive developmental assessment of SCDAP/RELAP5/MOD3.1 $1^{1,2}$. The first step was the most complex and involved using the TMI-2 system model to establish the influence of uncertainties in thermalhydraulic boundary conditions (i.e., makeup flow rates and the rate and quantity of water injected into the reactor vessel during the $2 \mathrm{~B}$ pump transient) on primary system pressure, reactor vessel water level, and core damage progression. A best-estimate calculation was then performed, using makeup flow rates that predicted a core damage state similar to the hypothesized state prior to the $2 \mathrm{~B}$ pump transient, and the results were compared to core and reactor vessel damage estimates derived from postaccident visual and analytical investigations. ${ }^{4,5}$

\section{SCDAP/RELAP5 TMI-2 MODEL}

As mentioned in the introduction, the SCDAP/RELAP5/MOD3. $1^{6}$ computer code is designed to analyze nuclear reactor accidents, particularly severe accidents. It includes modules to simulate reactor thermal-hydraulics (RELAP5), core damage progression (SCDAP), the thermal behavior of debris that slumps into the lower head of the reactor vessel (COUPLE), and a materials property library (MATPRO) that is called by each module. The input for each of these modules, except MATPRO, is described in this section. 


\subsection{RELAP5 Input}

The RELAP5 portion of the TMI-2 model was derived from an Oconee plant model described in Reference 7. Both TMI-2 and oconee are PWR's having a two-by-four coolant loop configuration, i.e., two primary coolant loops, each containing one hot leg and two cold legs. Both plants were built by Babcock \& wilcox in the $1970^{\prime} s$ and have nearly identical design and operating characteristics. Consequently, the Oconee RELAP5 model was easily adapted to represent TMI-2. Figures 1 through 4 are nodalization diagrams of the reactor vessel, primary piping, steam generators, and pressurizer, respectively.

\subsubsection{Reactor Vessel}

The RELAP5 vessel model (Figure 1) represents all major components of the reactor vessel, including the inlet annulus, downcomer, lower plenum, core, core bypass, upper plenum, upper head, reactor vessel vent valves, and the control rod guide tube brazements. The core is divided into five parallel channels, each consisting of ten subvolumes (branch components 10 through 59). Lateral flow between adjacent core channels is simulated using the RELAP5 cross-flow model. Annulus component 570 represents the downcomer and pipe component 510 the core bypass. Branch components 505 and 575 represent the lower plenum. The upper plenum is also divided into five parallel regions that are connected laterally by cross-flow junctions. This arrangement allows for the development of in-vessel natural circulation under appropriate conditions. Valve component 542 represents the reactor vessel vent valves and pipe components 580 through 584 the guide tube brazements. Fifty-one heat structures are used to model the thermal behavior of reactor vessel metal structures. 


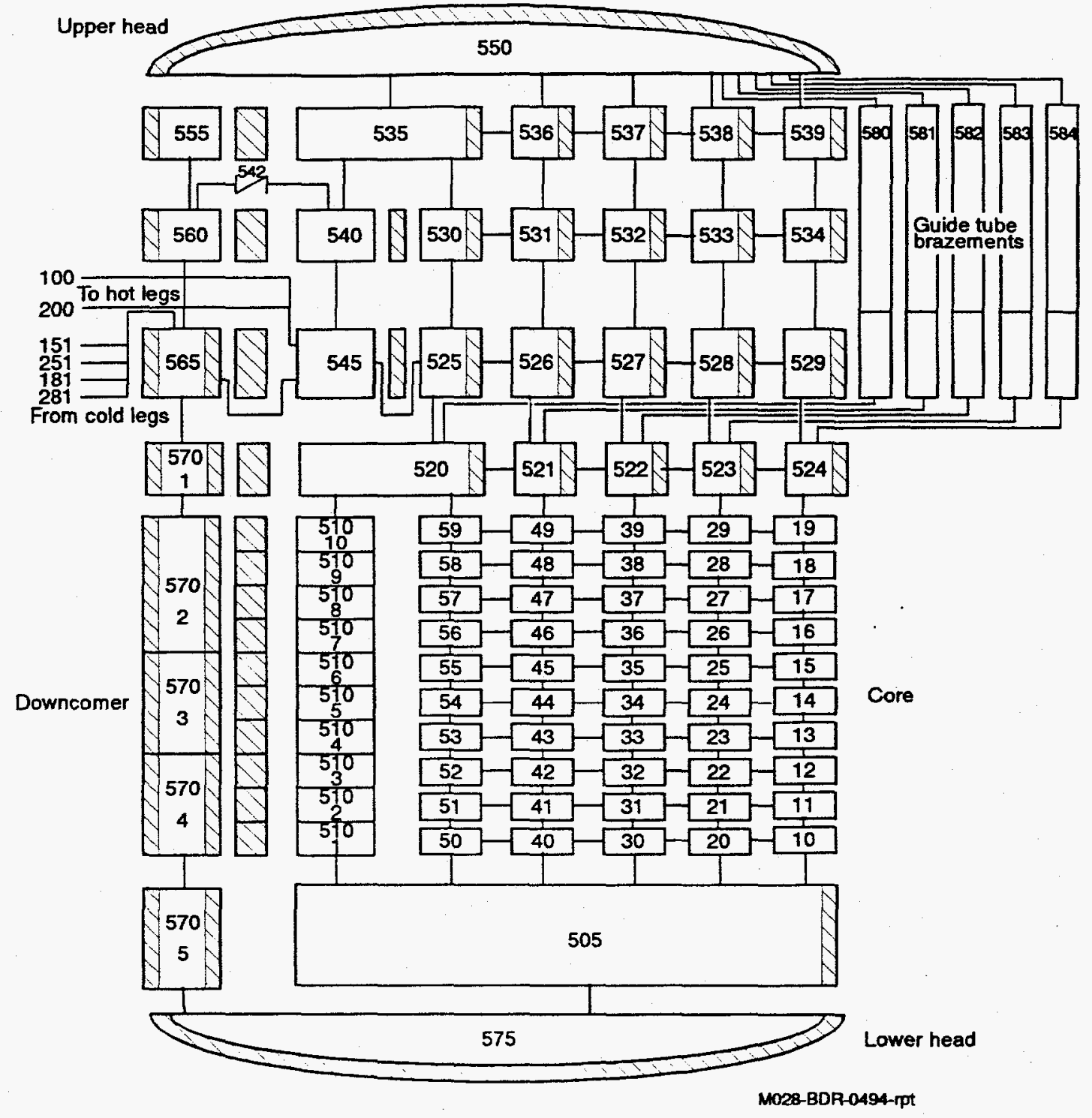

Figure 1: RELAP5 nodalization of the reactor vessel and core. 


\subsubsection{Primary Piping}

Figure 2 is a nodalization diagram of primary coolant loop A, which consists of one hot leg (components 100 through 114), one steam generator (discussed subsequently), two pump suction legs (pipe components 130 and 160), two reactor coolant pumps (pump components 135 and 165), and two cold legs (components 140 through 151 and 170 through 181). Primary loop $B$ is identical to loop A, except it does not contain a letdown flow path (timedependent junction 193) or connections to the pressurizer spray and surge lines. The component numbers for loop $B$ are also increased by 100 (e.g., the primary pumps are numbered 235 and 265 rather than 135 and 165). The high pressure injection (HPI) system is represented by time-dependent volumes 710 and 715 , which are connected to the cold legs by time-dependent junctions 711 and 716. HPI flow is assumed to be split equally between the $A$ and $B$ loops, while makeup flow is injected only into the $B$ loop. Eighteen heat structures (per loop) are used to model the thermal behavior of the primary piping.

\subsubsection{Steam Generators}

The nodalization of steam generator $A$ is shown in Figure 3. Steam generator $B$ is identical except that all component numbers are increased by 100. The boiler region is divided into two parallel flow channels: an inner channel (volumes 310 through 323), connected to $90 \%$ of the steam generator tubes, and an outer channel (volumes 360 through 373), connected to $10 \%$ of the steam generator tubes. Cross-flow junctions connect the two boiler regions. Auxiliary feedwater is normally injected into the top of the $10 \%$ region. Pipe component 120 represents the primary side of the steam generator tube bundle, while branch components 115 and 125 represent the inlet and outlet plena. The steam 


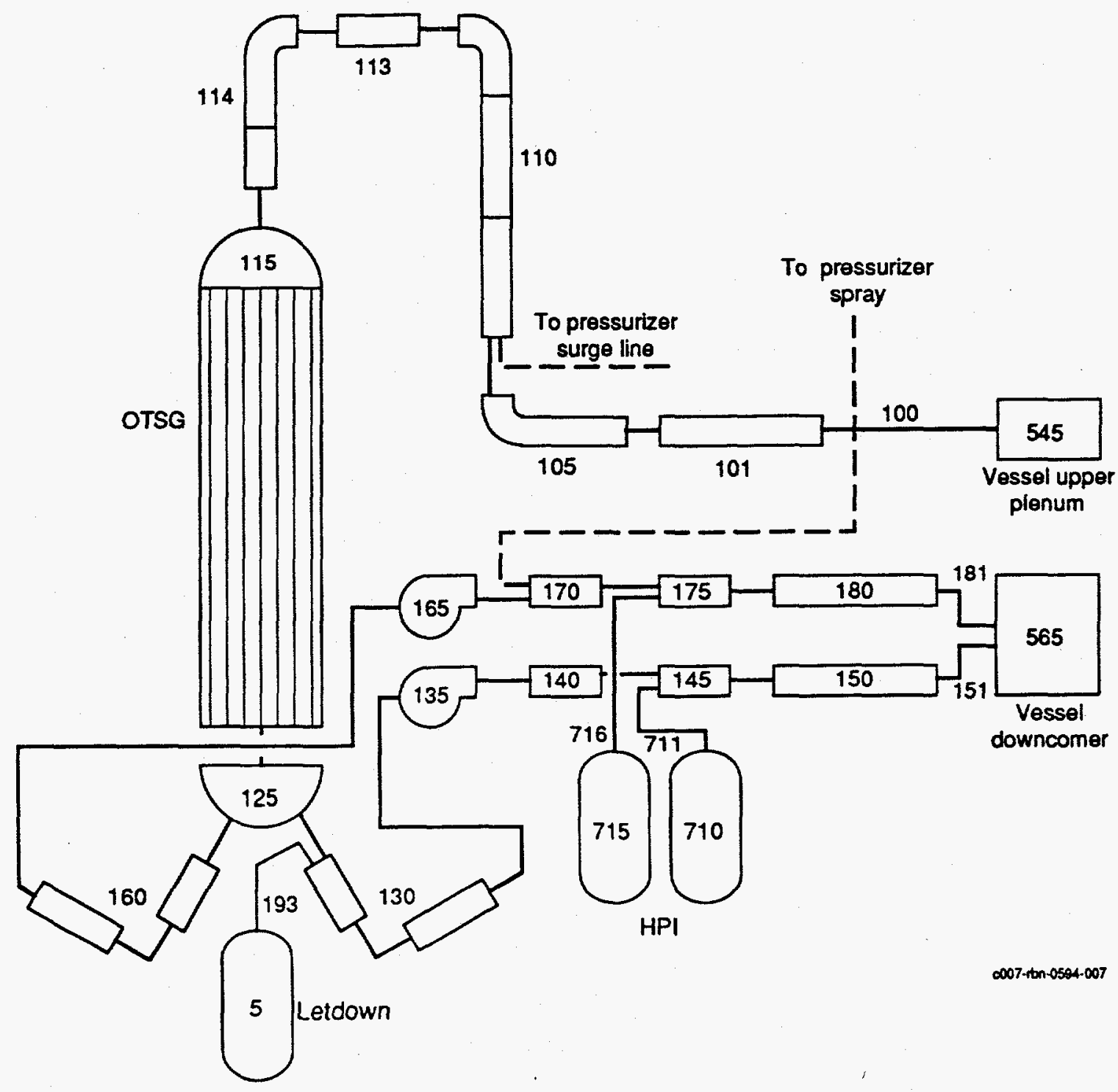

Figure 2. RELAP5 nodalization of primary coolant loop A. 
generator downcomer is modeled by component 305 , and components 345 and 350 represent the steam line. To preheat the feedwater, a portion of the steam flow is bled into the downcomer through an aspirator near mid-boiler (modeled with a junction between components 365 and 305). Valve component 821 represents the main steam valve. Forty-three heat structures are used to model the thermal behavior of steam generator metal structures (including the tube bundle).

It should be noted that for all the calculations reported here, auxiliary feedwater was injected into the steam generator downcomer rather than onto the tube bundle as indicated in Figure 3. A previous TMI-2 analyses using SCDAP/RELAP5 ${ }^{8}$ indicated that feedwater injection directly onto the steam generator tubes resulted in too much primary-side condensation, which in turn caused the primary system pressure to be underpredicted. It should also be noted that the nodalization of the steam generators differs somewhat from that recommended in the SCDAP/RELAP5 user's guide. ${ }^{6}$ Although the boiler is divided into two parallel regions, the tube bundle (pipe 120) is not. Dividing the tube bundle into a $10 \%$ region and a $90 \%$ region may alleviate some of the condensation problems encountered previously.

\subsubsection{Pressurizer}

Figure 4 is a nodalization diagram of the pressurizer. The pressurizer upper head is modeled with branch component 615 and the pressurizer cylindrical body and lower head with pipe component 610. Valve 801 represents the pilot operated relief valve (PORV). Pipes 600 and 620 represent the pressurizer surge and spray lines, respectively, and valve 616 models the spray valve. Single volume component 949 represents the containment building, which is initially filled with air at $101 \mathrm{kPa}$. Twelve 


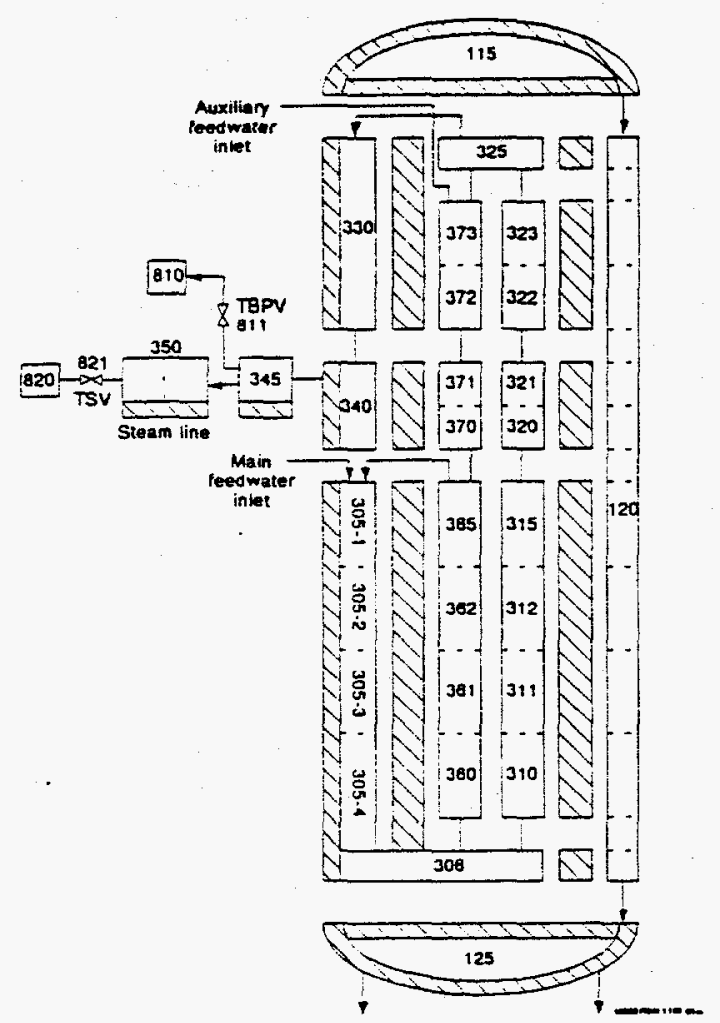

Figure 3. RELAP5 nodalization of steam generator A. SRV PORV

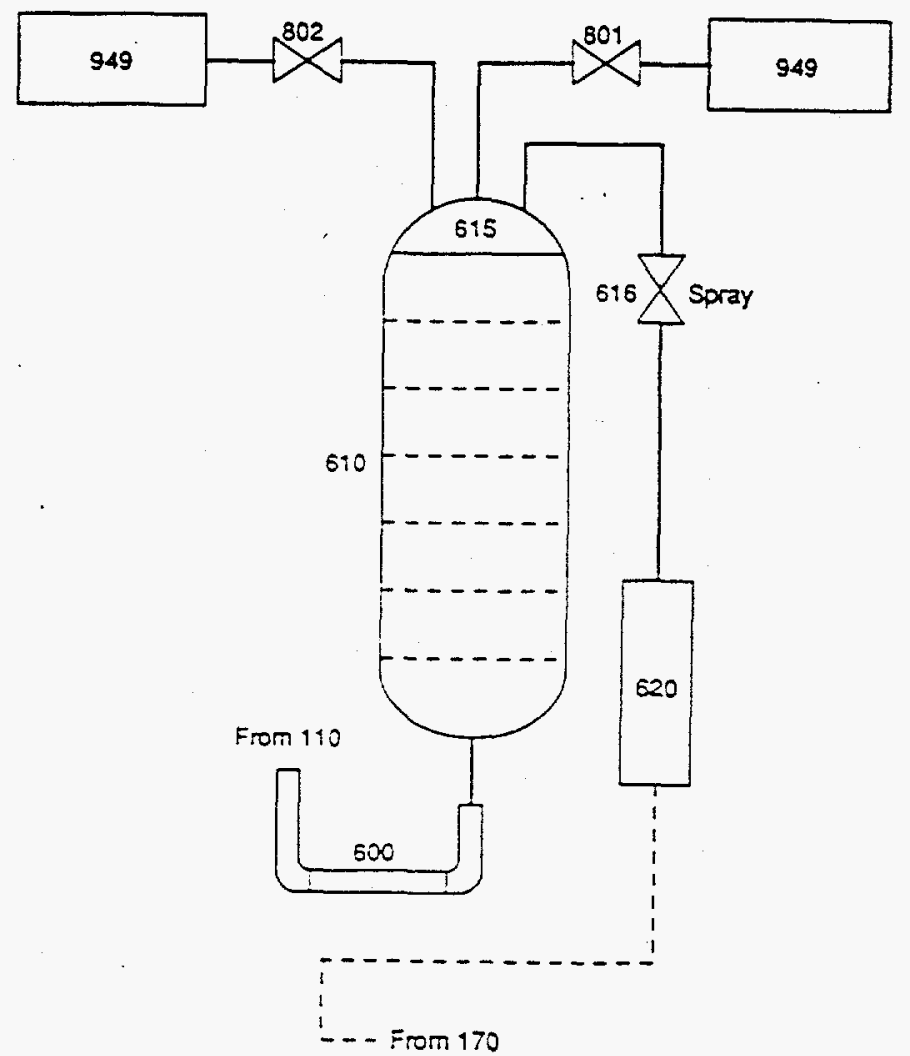

Figure 4. RELAP5 nodalization of the pressurizer. 
heat structures are used to model the thermal behavior of the pressurizer shell, upper and lower heads, and the surge line; one heat structure is used to simulate operation of the pressurizer heaters; and five heat structures are used to model the thermal behavior of the containment building.

It should be noted that critical flow through the PORV is modeled using the homogeneous (single velocity) two-phase flow option in RELAP5. Previous TMI-2 calculations using SCDAP/RELAP5 ${ }^{8}$ have shown that this option better predicts the PORV flow history reported in the TMI-2 initial and boundary conditions (ICBC) data base than the nonhomogeneous option. [The PORV flow rates reported in Reference 9 were calculated using the Henry-Fauske critical flow model for subcooled conditions and the homogeneous equilibrium critical flow model (HEM) for two-phase conditions. ${ }^{10} \mathrm{~J}$ It should also be noted that for all the calculations reported here, a check valve was installed between the pressurizer and the surge line at $139 \mathrm{~min}$ to prevent the pressurizer from draining. In preliminary calculations, the pressurizer drained completely after the PORV block valve was closed at $139 \mathrm{~min}$, which effectively terminated core heatup. More accurate representations of the surge line and pressurizer might eliminate some of the problems encountered in this and previous TMI-2 analyses. For example, the junction connecting the surge line to hot leg $A$ should be oriented horizontally rather than vertically (to reflect its true alignment) and the countercurrent flow limitation (CCFL) model should be activated at the junction connecting the surge line to the pressurizer, rather than at the hot leg junction. Also, the CCFL input parameters (currently set to default values) should be reviewed for applicability. 


\subsection{SCDAP Input}

The TMI-2 core was divided into five regions for this analysis by grouping similarly powered fuel assemblies together. Figure 5 is a cross section of the core illustrating each region and its average radial power peaking factor. Table 1 lists the average axial power peaking factors for each region. Both the axial and radial peaking factors were derived from detailed peaking factor data presented in Appendix A of Reference 9. one SCDAP fuel rod component is used to represent all the fuel rods in each core region. One SCDAP control rod component is used to represent all the full- and part-length control rods, all the guide tubes (including those containing burnable poison rods), and all the instrument tubes in each core region (except region five which contains no control rods)." The control rod radii in regions one through four have been adjusted so that the total mass of Zircaloy, Ag-Cd-In absorber, and stainless steel is conserved (the burnable poison mass is neglected). In core region five, a dummy fuel rod component is used to represent all the guide and instrument tubes. By specifying a small fuel diameter and zero power, this component essentially behaves as a hollow zircaloy tube. The SCDAP grid spacer model is used to represent the eight Inconel spacer grids that are uniformly distributed along the length of each fuel assembly.

Much of the SCDAP input data was obtained from Reference 11 and is summarized in Table 2. Table 3 lists the total number of fuel assemblies, fuel rods, control rods, burnable poison rods, and orifice rods in each core region.

a. Component models specifically for burnable poison rods and instrument tubes have not been developed for SCDAP/RELAP5. 


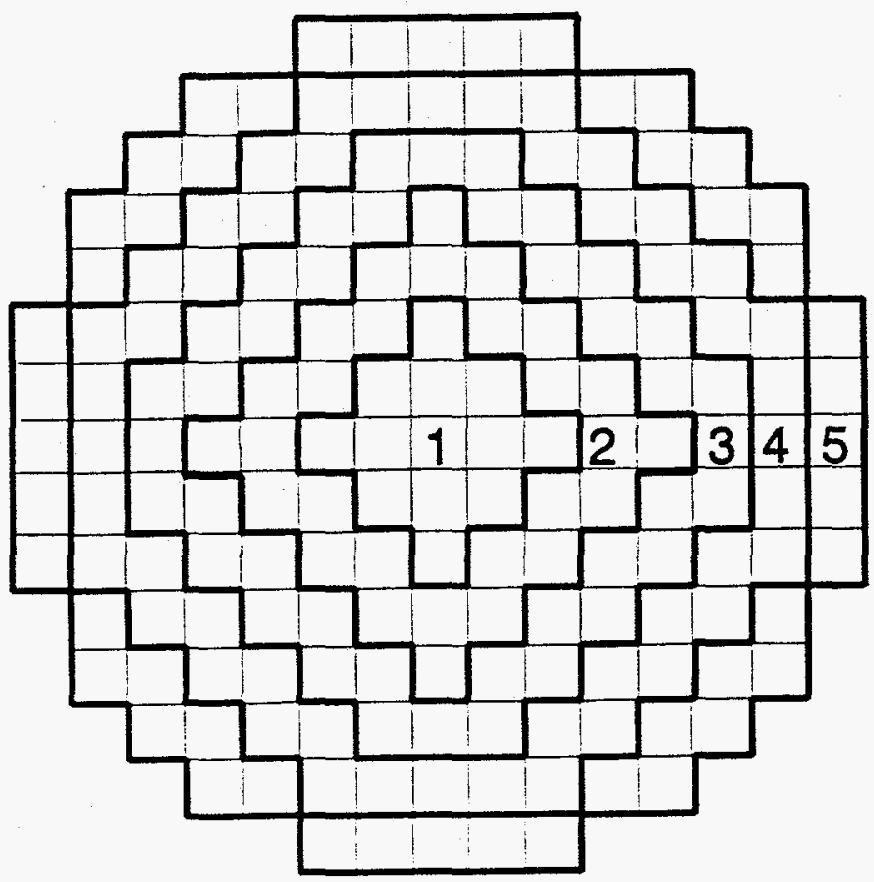

Radial

Region Peaking Factor

$\begin{array}{ll}1 & 1.245 \\ 2 & 1.136 \\ 3 & 1.074 \\ 4 & 1.061 \\ 5 & 0.733\end{array}$

M028-BDR-0494-001

Figure 5. Cross-section of core showing fuel assembly grouping and radial peaking factors. 
Table 1. TMI-2 axial power peaking factors.

Distance From Bottom of Fuel (m)

0.183

0.549

0.914

1.280

1.646

2.012

2.377

2.743

3.109

3.475
0.665

0.933

1.134

1.216

1.248

1.262

1.225

1.078

0.792

0.448
0.674

0.919

1.099

1.164

1.202

1.221

1.232

1.124

0.853

0.512
Power Factor

Region 3 Region 4 Region 5
0.729

0.690

0.670

0.962

0.951

0.944

$$
1.112
$$

1.132

1.145

1.112

1.168

1.213

\subsection{8}

1.192

1.238

1.153

1.206

1.248

\subsection{1}

1.241

1.222

1.174

1.131

1.083

0.880

0.834

0.794

0.488

0.455

0.442

Table 2. Total fuel assemblies, fuel rods, and control rods in each core region.

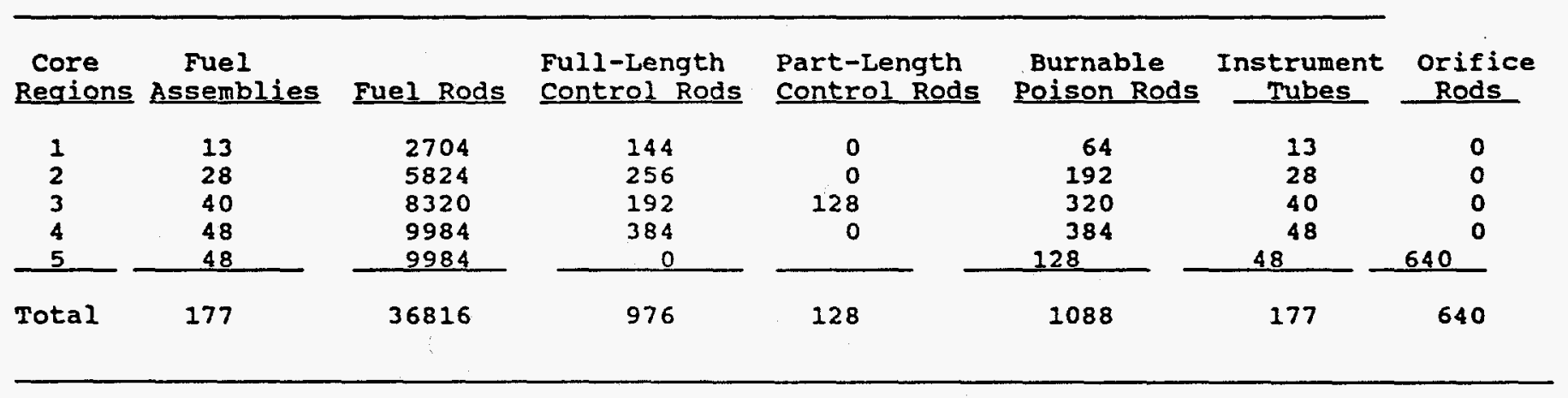


Table 3. SCDAP input parameters.

\section{Parameter}

Fuel Rods

\section{Active height (m)}

Rod Pitch (m)

Cladding inner radius (m)

cladding outer radius (m)

Fuel pellet radius (m)

Fuel density (\% T.D.)

Mass of He fill gas (kg) (estimated)

Upper and lower plenum

void volume $\left(\mathrm{m}^{3}\right)$

Control Rods

Guide tube inner radius ( $m$ )

Guide tube outer radius (m)

cladding inner radius (m)

Cladding outer radius ( $m$ )

Absorber radius (m)

Instrument Tubes

Tube inner radius (m)

Tube outer radius (m)

Grid Spacers

Grid spacer mass ( $\mathrm{kg}$ )

Grid spacer height (m)

Grid spacer thickness (m)

\section{Value}

\subsection{8}

$1.443 \times 10^{-2}$

$4.788 \times 10^{-3}$

$5.461 \times 10^{-3}$

$4.699 \times 10^{-3}$

92.5

$1.265 \times 10^{-4}$

$1.490 \times 10^{-5}$

$6.325 \times 10^{-3}$

$6.731 \times 10^{-3}$

$5.055 \times 10^{-3}$

$5.588 \times 10^{-3}$

$5.004 \times 10^{-3}$

$5.601 \times 10^{-3}$

$6.261 \times 10^{-3}$

0.86

$3.30 \times 10^{-2}$

$5.08 \times 10^{-4}$ 


\subsection{COUPLE Input}

The COUPLE module is used to calculate the heatup of core debris that slumps into the lower head of the reactor vessel. The lower head is represented by a two-dimensional $(r, z)$, axisymmetric, finite-element mesh containing 320 nodes and 285 elements (Figure 6). Radially, the lower head wall is divided into three heat conduction elements. The remaining elements (those internal to the lower head) are initially filled with primary coolant, which can either boil away or be displaced by core debris. Convection and radiation heat transfer are modeled at all interfaces between the coolant and core debris. The outside surface of the lower head is assumed to be adiabatic.

\subsection{Initial conditions}

Table 4 compares the initial conditions in the SCDAP/RELAP5 model to those recommended in the ICBC data base." With the exception of steam generator pressures and temperatures, the calculated (or specified) initial conditions are in good agreement with the data base. For steady-state calculations, a control system is used in the SCDAP/RELAP5 model to automatically adjust steam generator pressures (by varying the flow areas of the main steam valves) until user-specified cold leg temperatures are obtained. For simplicity, the target coolant temperature for all four cold legs was specified to be $565 \mathrm{~K}$. Table 5 compares the calculated initial conditions on the secondary side of each steam generator to the initial conditions recommended in Reference 12. It is seen that the calculated steam generator pressures are in much better agreement with the Reference 12 data

a. All initial conditions correspond to the time of turbine trip: 04:00:37 hours on March 28, 1979. 


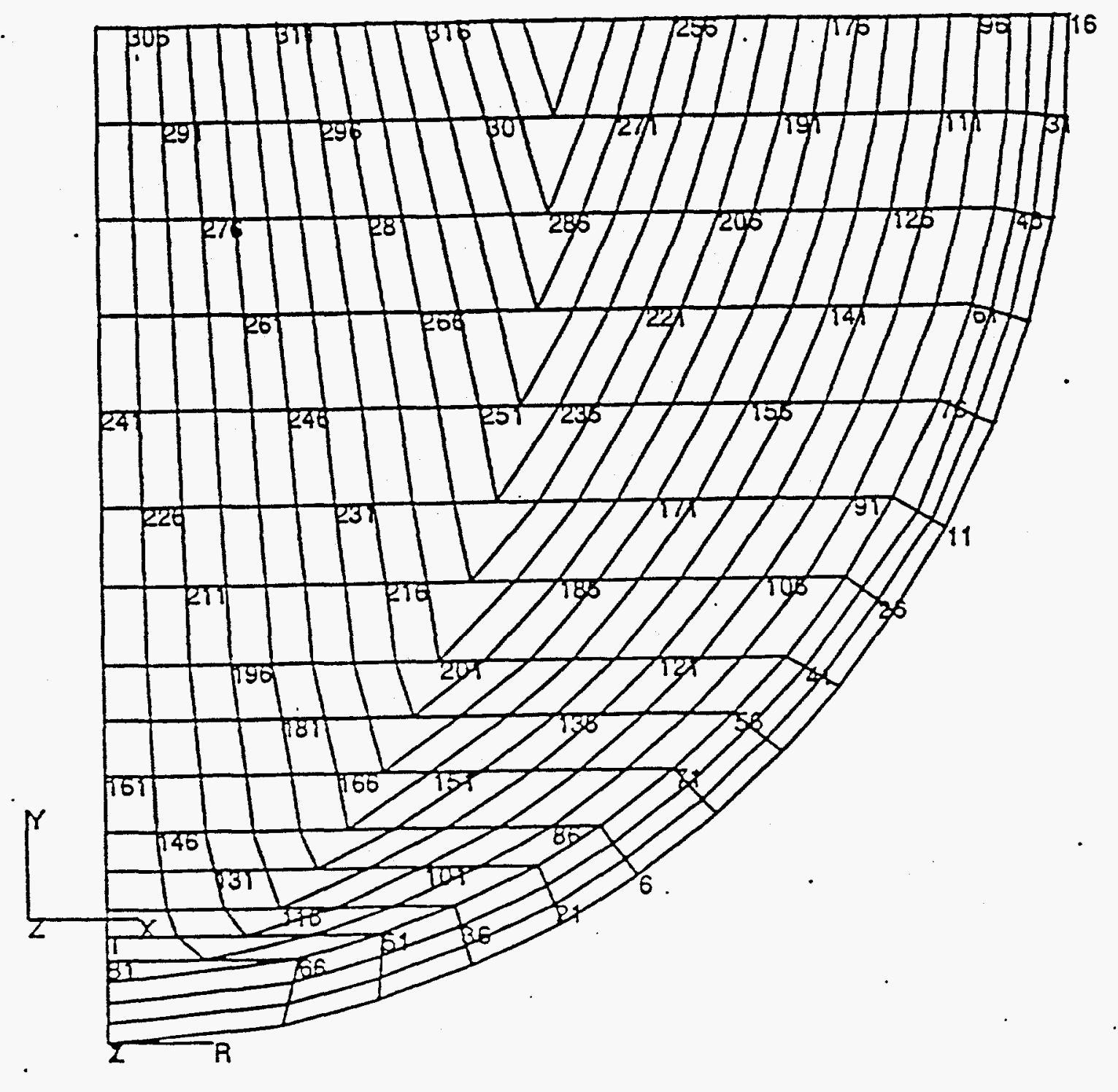

Figure 6. COUPLE finite element mesh used to model the lower head of the reactor vessel. 
Table 4. TMI-2 initial conditions at turbine trip.

\begin{tabular}{|c|c|c|}
\hline Parameter & $\begin{array}{c}\text { ICBC } \\
\text { Data Base }\end{array}$ & SCDAP/RELAP5 \\
\hline Reactor power (MW) & 2700 & \\
\hline Primary system pressure (Mpa) & 15.2 & 15.2 \\
\hline $\begin{array}{l}\text { Pressurizer level (m) } \\
\text { Pressurizer heater power (Mw) }\end{array}$ & $\begin{array}{l}5.77 \\
1.39\end{array}$ & $\begin{array}{l}5.76 \\
1.39\end{array}$ \\
\hline $\begin{array}{l}\text { Loop A coolant flow }(\mathrm{kg} / \mathrm{s}) \\
\text { Loop B coolant flow }(\mathrm{kg} / \mathrm{s})\end{array}$ & $\begin{array}{l}8280 \\
8560\end{array}$ & \\
\hline $\begin{array}{llll}\text { Cold leg temperature } 1 \mathrm{~A} & (\mathrm{~K}) \\
\text { cold leg temperature } 1 \mathrm{~B} & (\mathrm{~K}) \\
\text { Cold leg temperature } 2 \mathrm{~A} & (\mathrm{~K}) \\
\text { Cold leg temperature } 2 \mathrm{~B} & \text { (K) }\end{array}$ & $\begin{array}{l}561 \\
565 \\
548 \\
565\end{array}$ & $\begin{array}{l}565 \\
565\end{array}$ \\
\hline $\begin{array}{l}\text { Hot leg temperature loop A }(K) \\
\text { Hot leg temperature loop B }(\mathrm{K})\end{array}$ & $\begin{array}{l}592 \\
592\end{array}$ & $\begin{array}{l}593 \\
593\end{array}$ \\
\hline $\begin{array}{l}\text { Makeup flow }(\mathrm{kg} / \mathrm{s}) \\
\text { Letdown flow }(\mathrm{kg} / \mathrm{s}) \\
\text { PORV flow }(\mathrm{kg} / \mathrm{s})\end{array}$ & $\begin{array}{l}5.44 \\
4.18 \\
2.59\end{array}$ & $\begin{array}{l}0.0 \\
0.0 \\
0.0\end{array}$ \\
\hline $\begin{array}{l}\text { Steam generator A feedwater flow }(\mathrm{kg} / \mathrm{s}) \\
\text { Steam generator B feedwater flow }(\mathrm{kg} / \mathrm{s}) \\
\text { Feedwater temperature }(\mathrm{K})\end{array}$ & $\begin{array}{l}723 \\
717 \\
513\end{array}$ & \\
\hline $\begin{array}{l}\text { Steam generator A pressure (Mpa) } \\
\text { Steam generator B pressure (Mpa) }\end{array}$ & $\begin{array}{l}7.31 \\
7.24\end{array}$ & $\begin{array}{l}6.34 \\
6.28\end{array}$ \\
\hline $\begin{array}{l}\text { Steam generator A steam temperature (K) } \\
\text { Steam generator B steam temperature (K) }\end{array}$ & $\begin{array}{l}586 \\
585\end{array}$ & $\begin{array}{l}576 \\
582\end{array}$ \\
\hline
\end{tabular}


Table 5. Steam generator initial conditions.

Parameter

Main feedwater temperature (K)

Steam generator A feedwater flow $(\mathrm{kg} / \mathrm{s})$

steam generator B feedwater flow $(\mathrm{kg} / \mathrm{s})$

Steam generator A pressure (Mpa) ${ }^{2}$

steam generator B pressure $(\mathrm{Mpa})^{\mathrm{a}}$

Steam generator A steam temperature (K)

steam generator B steam temperature (K)

Steam generator A riser level (cm)

steam generator B riser level (cm)

Steam generator A downcomer level (cm)

steam generator B downcomer level (cm)

Steam generator A power (MW)

steam generator B power (MW)
Reference 12 SCDAP/RELAP5

513

722

718

723

717

6.38

6.24

6.34

6.28

586

586

576

582

526

197

538

183

660

559

669

543

1346

1339
1332

1378

a. The pressures reported in Reference 12 are average steam line pressures measured 10 to $0.1 \mathrm{~min}$ before turbine trip. 
than with the ICBC data base." Calculated steam generator coolant levels, however, differ considerably from those reported in Reference 12. For future calculations, the steam generator models should be adjusted to better represent the Reference 12 data (which the authors believe to be more appropriate). One way to accomplish this may be to increase the pressure drop across the tube support plates as was done for a TMI-2 analysis performed with the CATHARE code. ${ }^{13}$

\subsection{Boundary Conditions}

All boundary conditions, except HPI/makeup flow rates, were obtained from the ICBC data base (Reference 9). The HPI/makeup flow rate history reported in Reference 14 was adjusted until the time of core uncovery (as inferred from hot leg temperature measurements), the time of initial fuel rod cladding failure (as inferred from containment radiation measurements), and the primary system pressure history were predicted reasonably well.b Figure 7 shows the HPI/makeup flow rate history used for the best-estimate SCDAP/RELAP5 calculation discussed subsequently (Section 3) to that recommended in Reference 9. In a previous SCDAP/RELAP5 analysis of the TMI-2 accident, ${ }^{15}$ using a previous version of the code, better results were obtained by reducing the makeup flow rate from 4 to $2 \mathrm{~kg} / \mathrm{s}$ between 100 and $174 \mathrm{~min}$. In an analysis performed with the MELPROG/TRAC code, ${ }^{16}$ it was concluded that the makeup flow rate recommended in Reference 9 was too high between 12 and $100 \mathrm{~min}$. For that analysis, the flow was reduced

a. The pressures reported in Reference 12 are average steam line pressures measured 10 to $0.1 \mathrm{~min}$ before turbine trip.

b. The uncertainty in HPI/makeup flow is large, particularly between 100 and $174 \mathrm{~min} .{ }^{14}$ Consequently, as noted in Reference 15, one set of assumptions is probably as good or bad as another. 


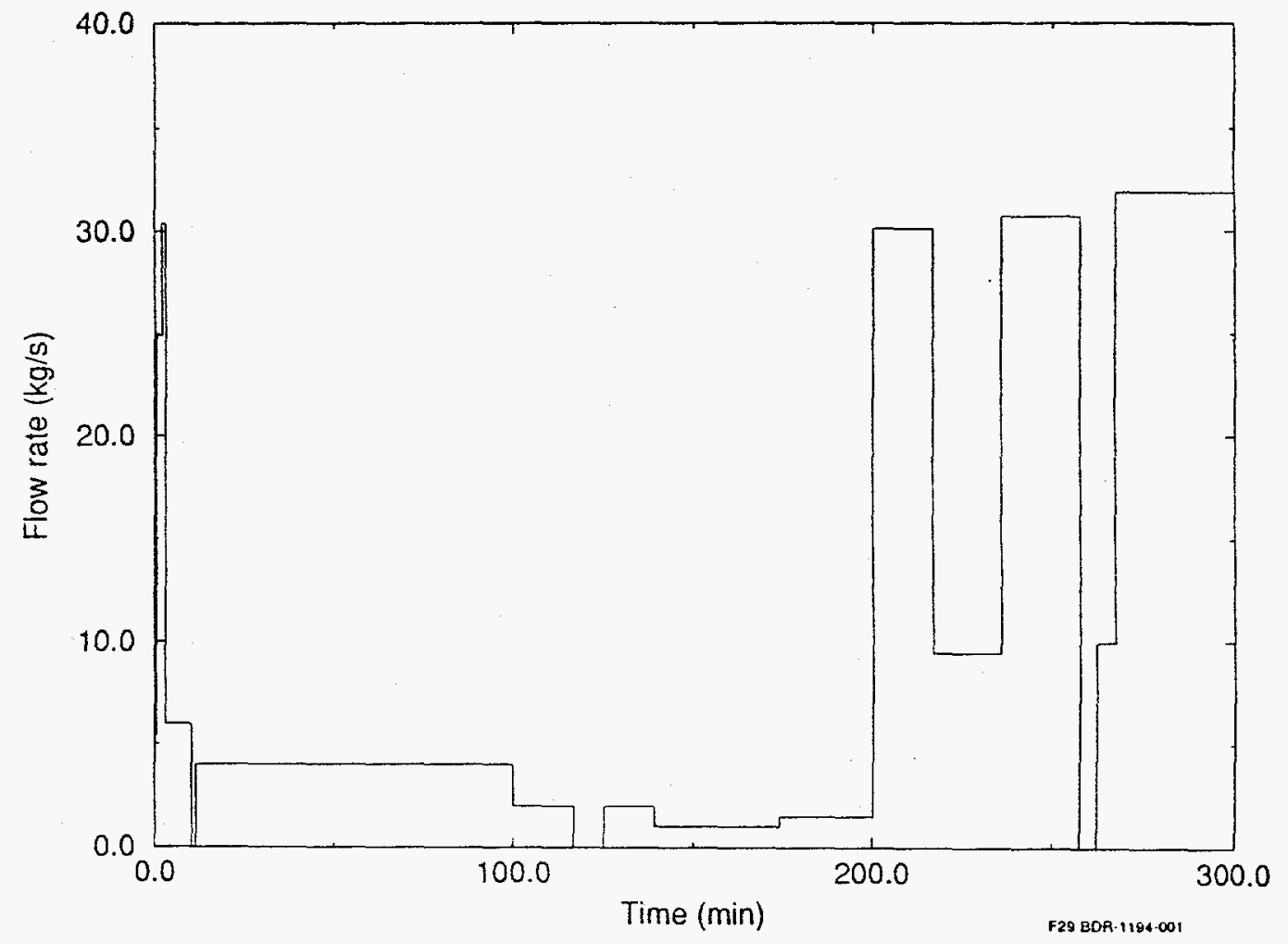

Figure 7. Makeup flow used for the best-estimate calculation. 20 
from 6.5 to $1 \mathrm{~kg} / \mathrm{s}$ between 12 and $100 \mathrm{~min}$ (which was the nominal value given in the original issue of the ICBC data base).

Calculated steam generator coolant levels, steam generator pressures, and letdown flow rates are compared to the Reference 9 data in Figures 8 through 12. For transient calculations, a control system is used in the SCDAP/RELAP5 model to automatically add auxiliary feedwater to the steam generators whenever calculated boiler levels are less than levels given in the ICBC data base. From Figures 8 and 9 , it is seen that this control system works reasonably well. Time-dependent volumes downstream of the main steam valves (volume 820 in Figure 3 ) are used to define the pressure history for each steam generator. The main steam valves (valve 821 in Figure 3) are modeled with check valves for transient calculations in order to prevent reverse flow. Consequently, calculated steam pressures can fall below measured pressures if the steam generator secondary boiloff rate is underpredicted (e.g., between 150 and $200 \mathrm{~min}$ in Figure 9). Core power as a function of time for the first $400 \mathrm{~s}$ following reactor scram was estimated using the reactor (point) kinetics and decay heat models in the RELAP5 code. The decay power from $400 \mathrm{~s}$ onward was obtained from Reference 17 . Figure 13 shows the reactor power versus time curve used in the SCDAP/RELAP5 model. 


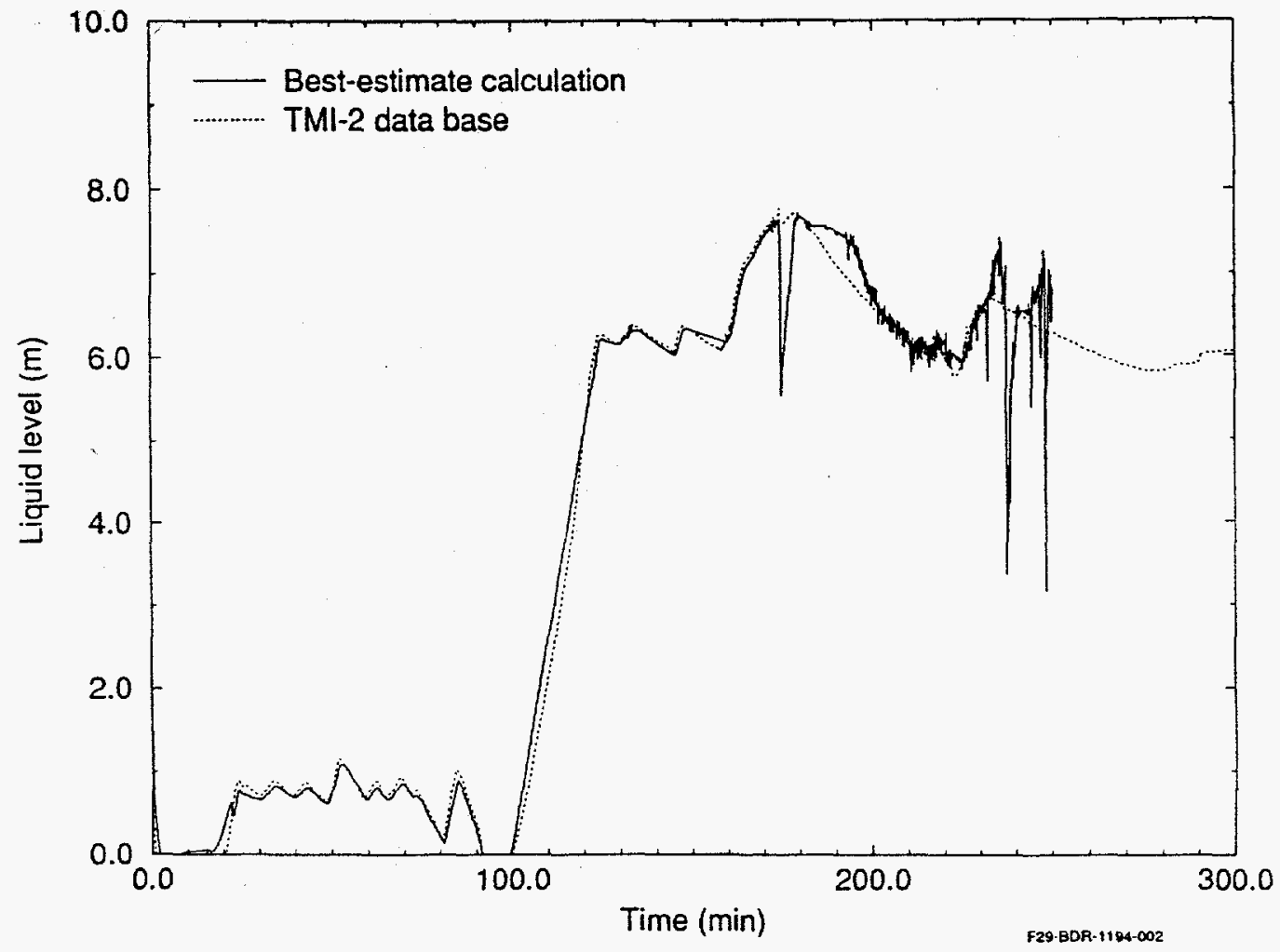

Figure 8. Calculated steam generator A coolant level compared to ICBC data base.

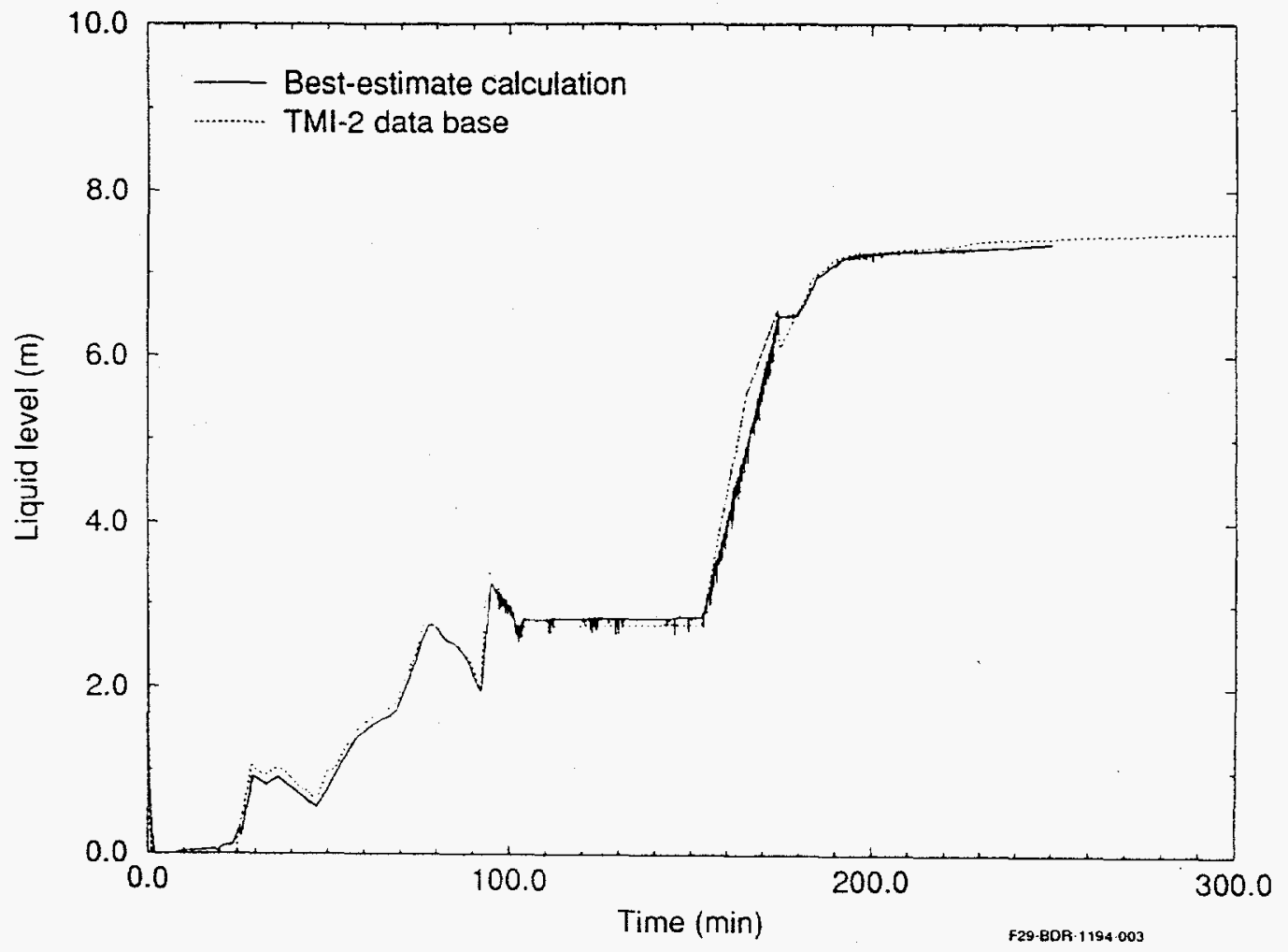

Figure 9. Calculated steam generator B coolant level compared to ICBC data base. 


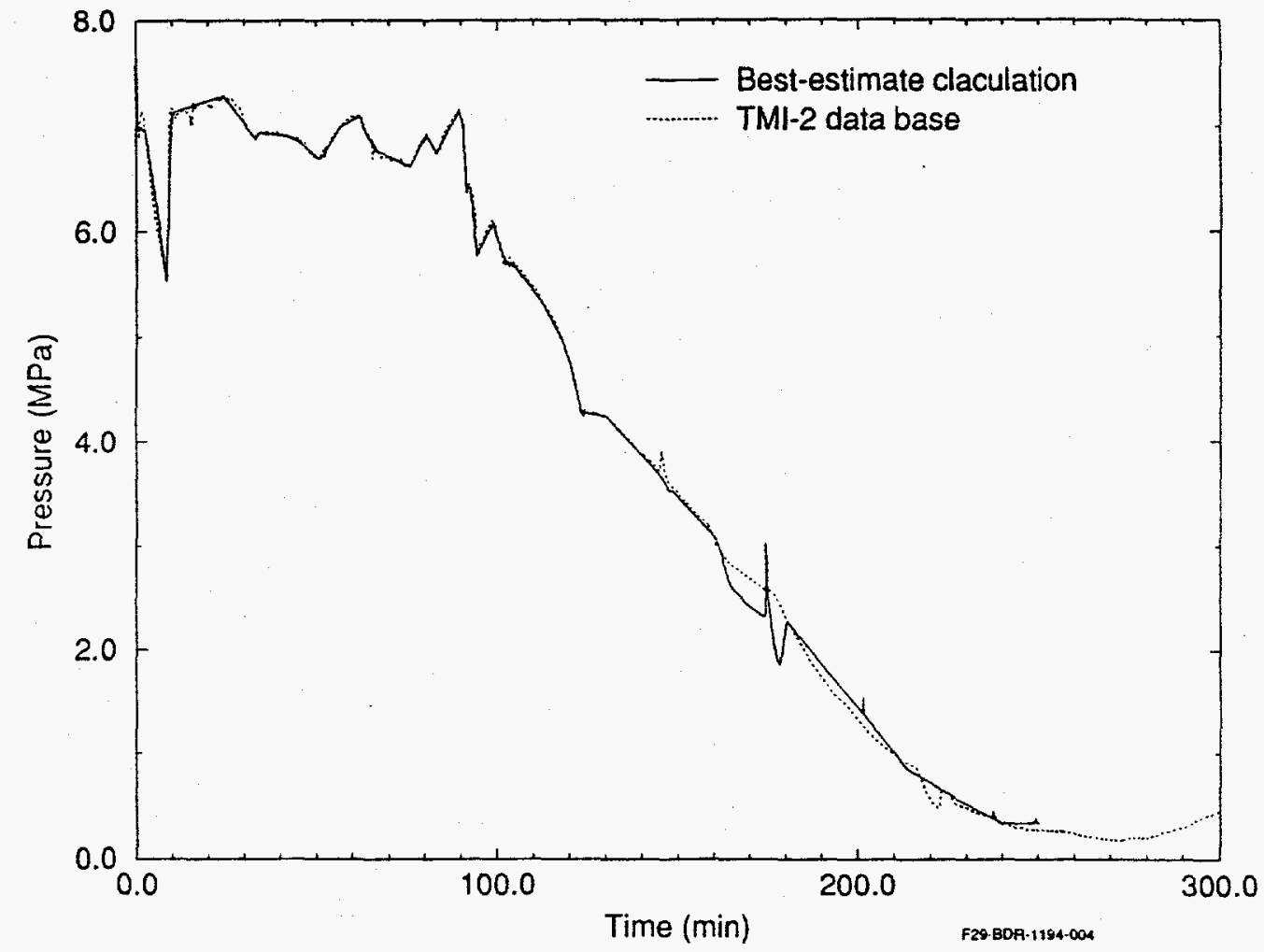

Figure 10. Calculated steam generator A pressure compared to ICBC data base.

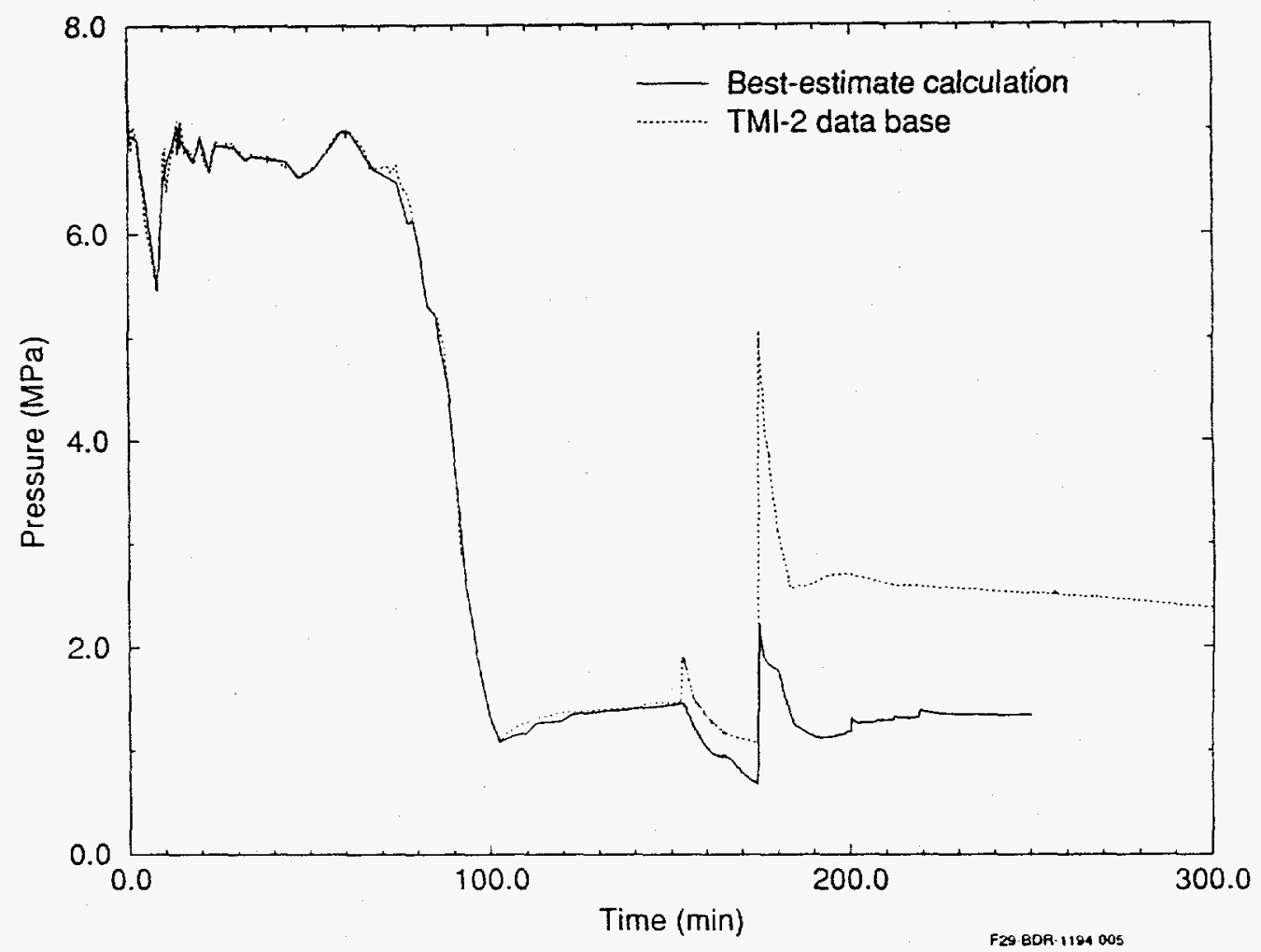

Figure 11. Calculated steam generator B pressure compared to ICBC data base. 


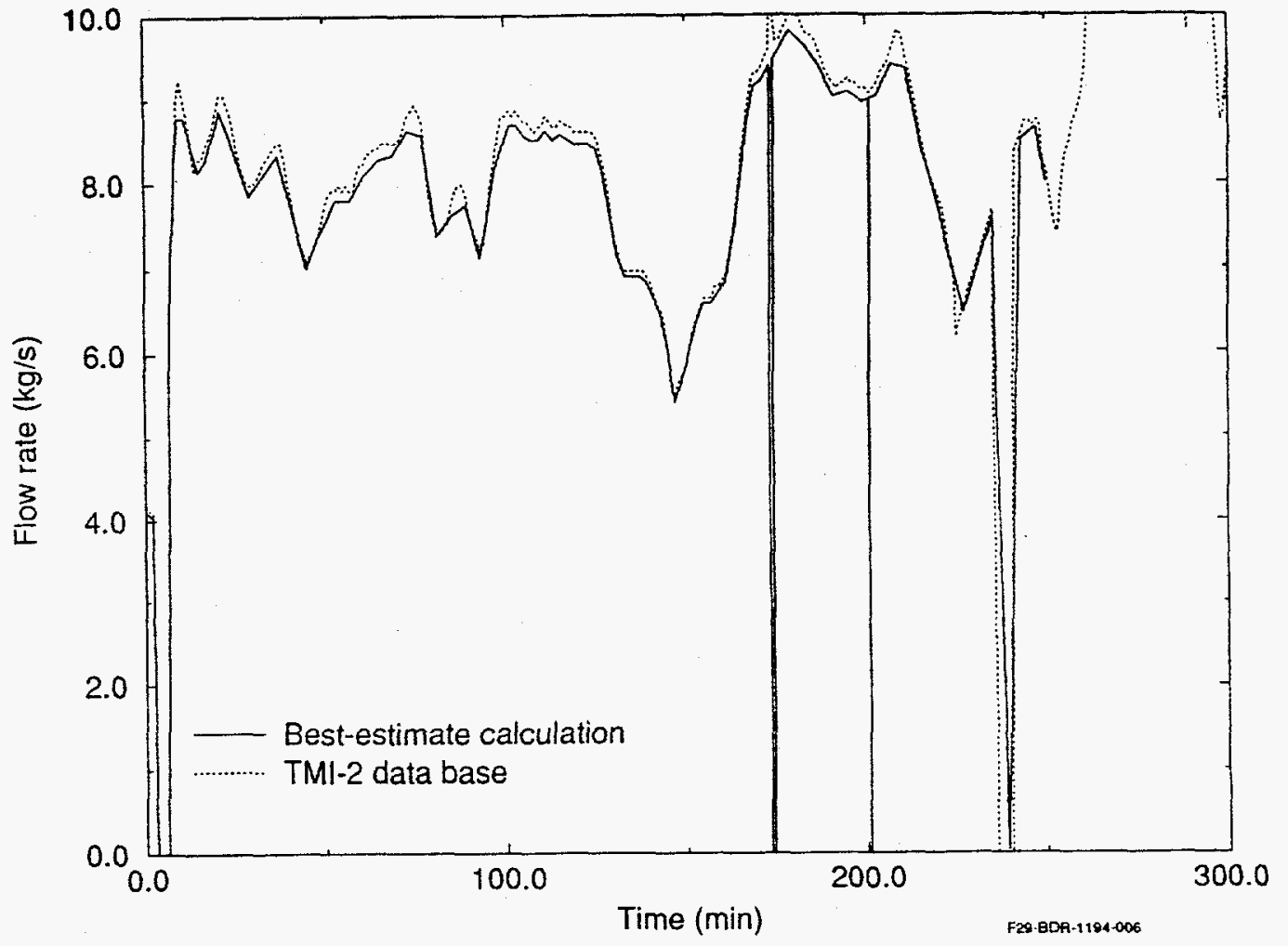

Figure 12. Calculated letdown flow rates compared to ICBC data base.

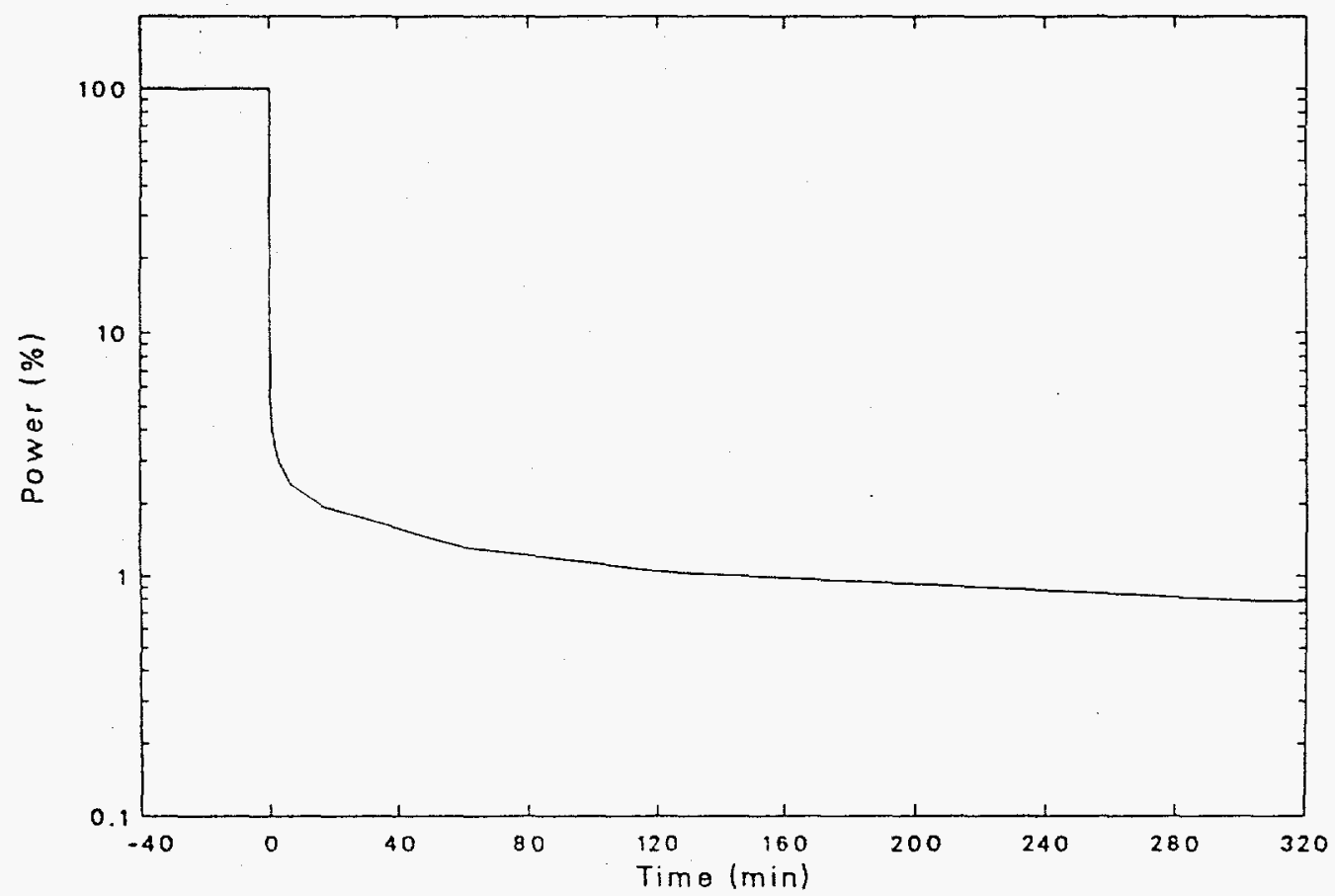

Figure 13. Reactor power versus time curve used for TMI-2 calculation. 


\section{RESULTS}

\subsection{Base case best-estimate calculation}

This section describes the results of the base case bestestimate analysis." Best-estimate conditions were based on the results of sensitivity studies, discussed in section 3.2 , performed with variations in the makeup flow rates. The bestestimate conditions were selected by comparing predicted system pressure, vessel liquid level, and initial clad failure time with those in the TMI-2 data base and the hypothesized core damage prior to the 2B-pump transient. The makeup flow rates used for the best-estimate calculation are shown in Figure 14. For comparison purposes, the nominal letdown flow, used as the other input flow boundary condition, makeup flow, and calculated flow through the PORV are shown in Figure 15. As shown in this figure, letdown flows were approximately $9 \mathrm{~kg} / \mathrm{s}$ and the calculated flows through the PORV varied between 10 and $55 \mathrm{~kg} / \mathrm{s}$, considerably greater than the makeup flow rates. Calculated flows through the PORV show large spikes associated with system pressure fluctuations prior to the closure of the block valve at 139 minutes.

As shown in Figure 16, the predicted pressure during the core heating and melting prior to the $2 \mathrm{~B}$-pump transient was significantly less than that measured. As discussed later, this is attributed to the underprediction of oxidation and hydrogen production during this phase of the accident. Figures 17 to 19

a. These results include the correction of an error in the oxidation model identified during the analysis of the results from the sensitivity studies on core liquid level. The error resulted in the suppression of the oxidation in a region that contained relocated material due to the interaction of Inconel spacer grids with fuel rod cladding. 

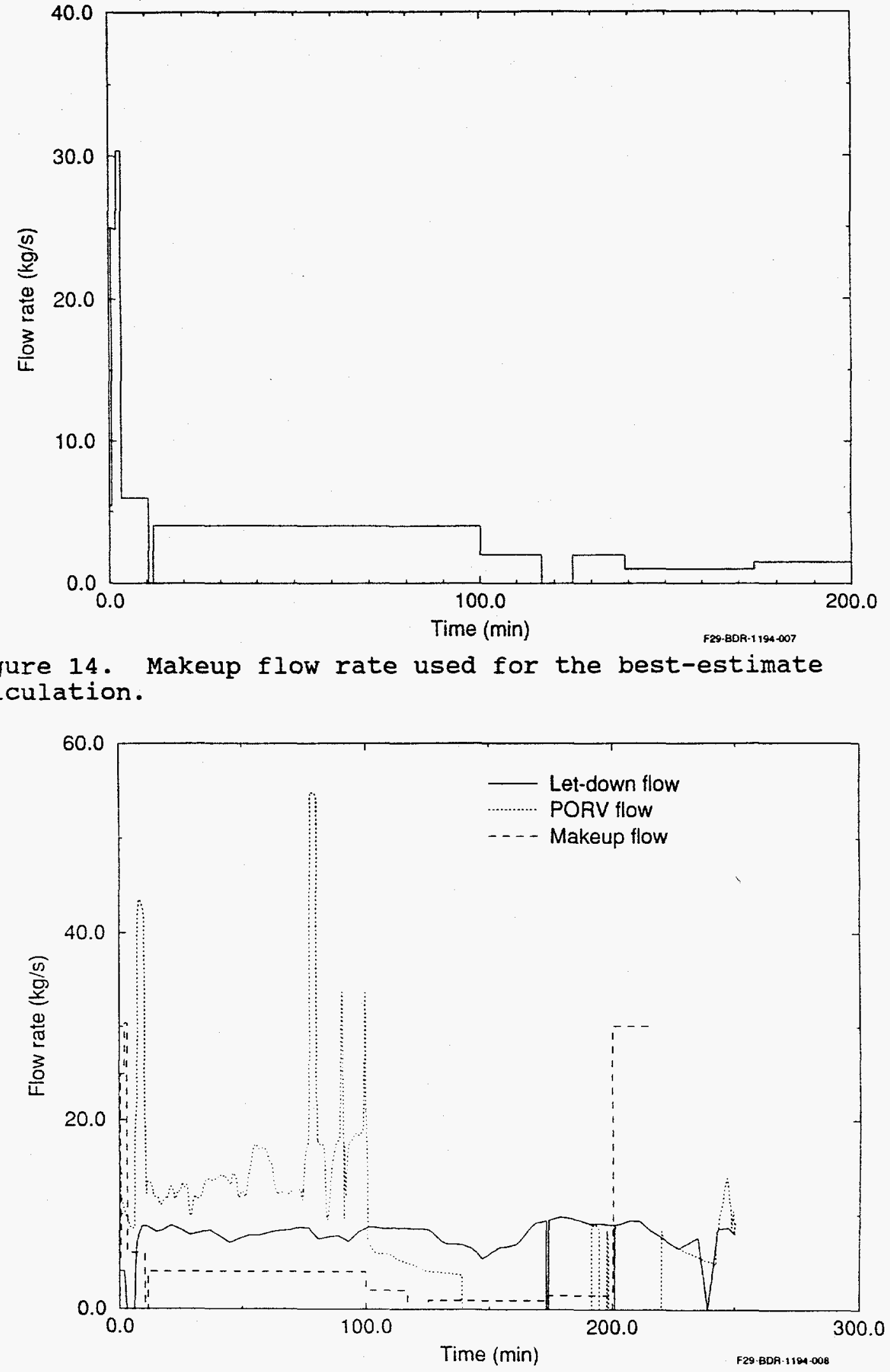

Figure 15. Comparison of letdown, makeup, and, PORV flow rates. 


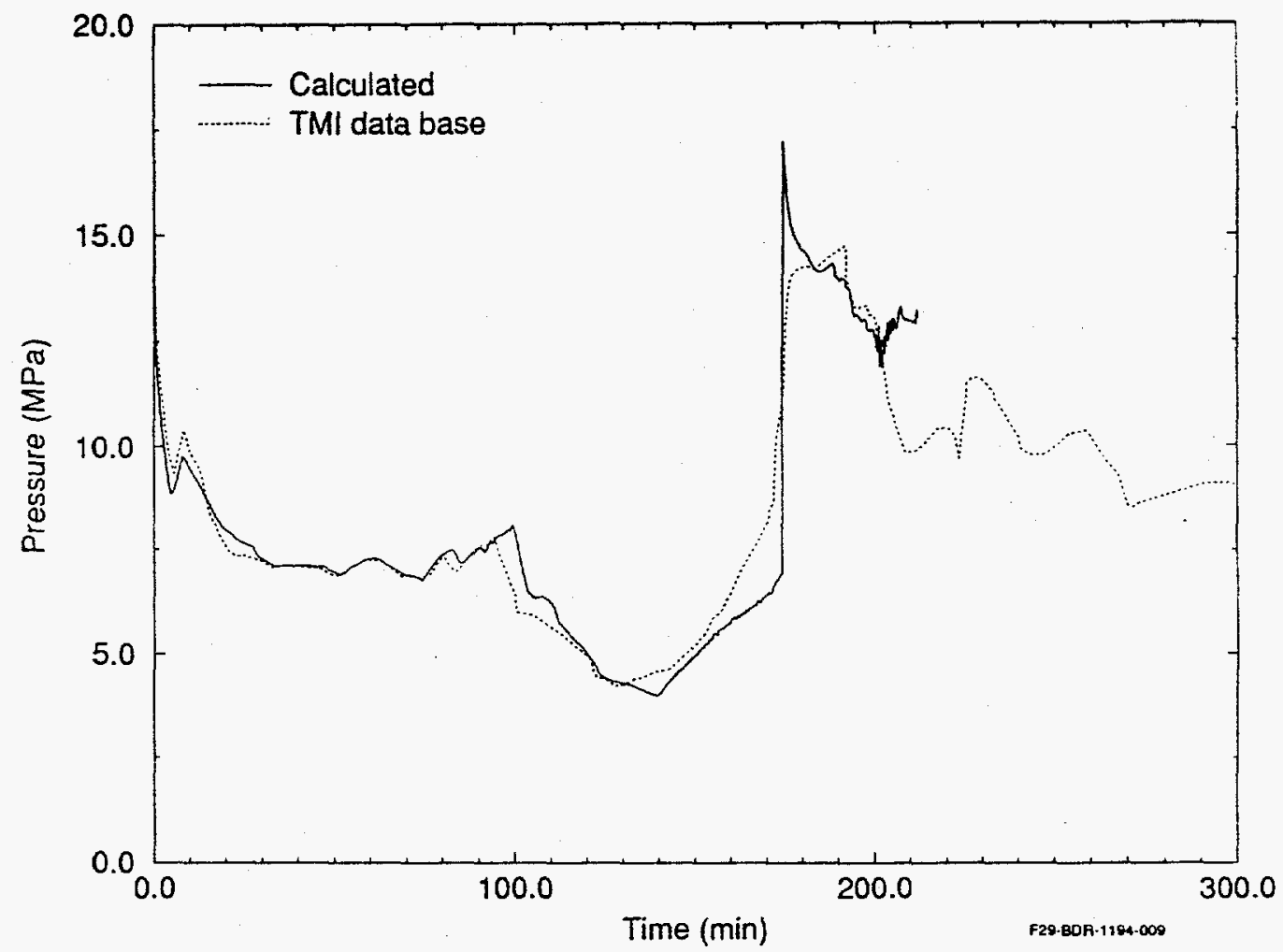

Figure 16. Calculated best-estimate and measured pressures.

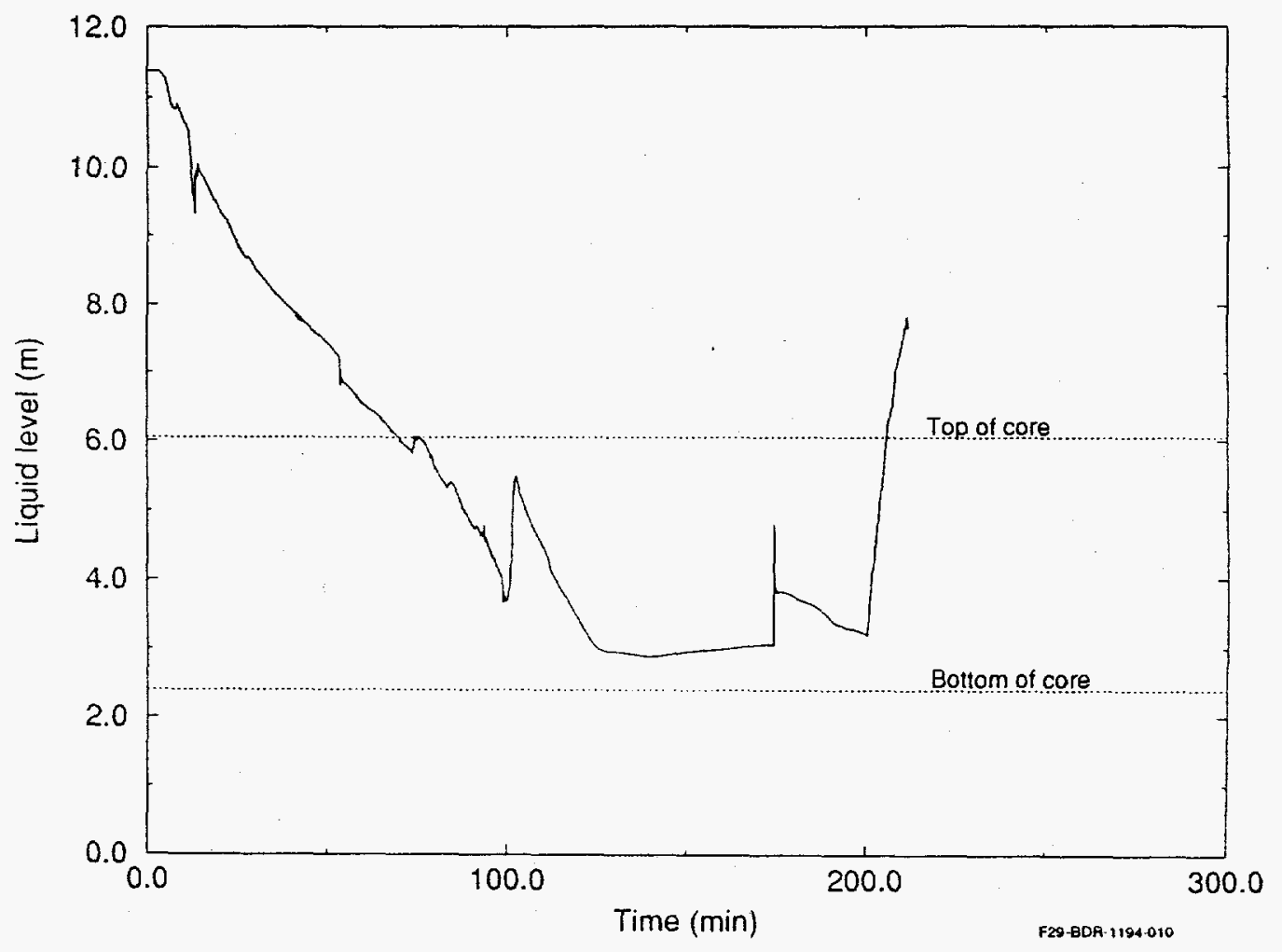

Figure 17. Predicted best-estimate collapsed liquid level. 


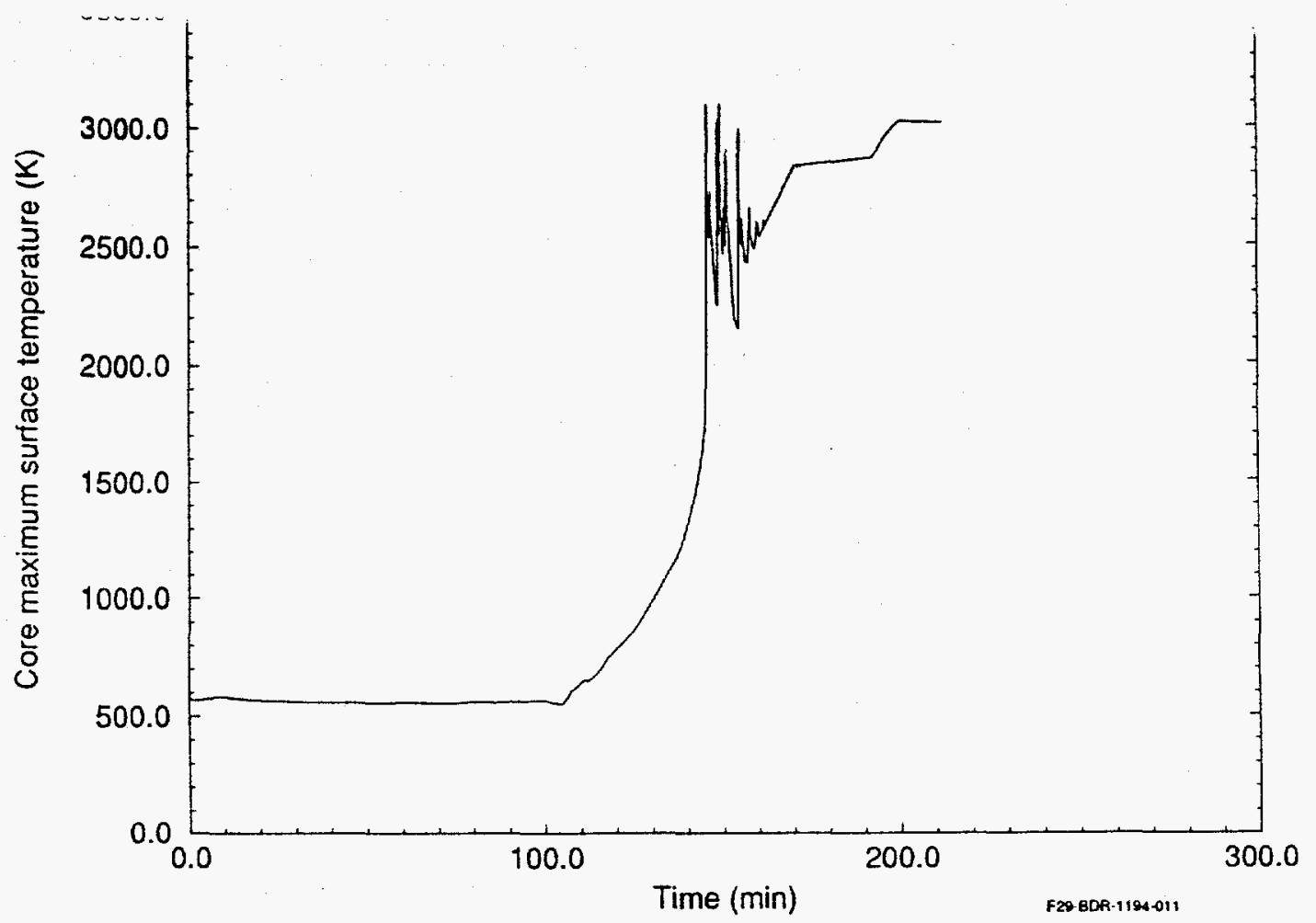

Figure 18. Predicted best-estimate maximum core temperature.

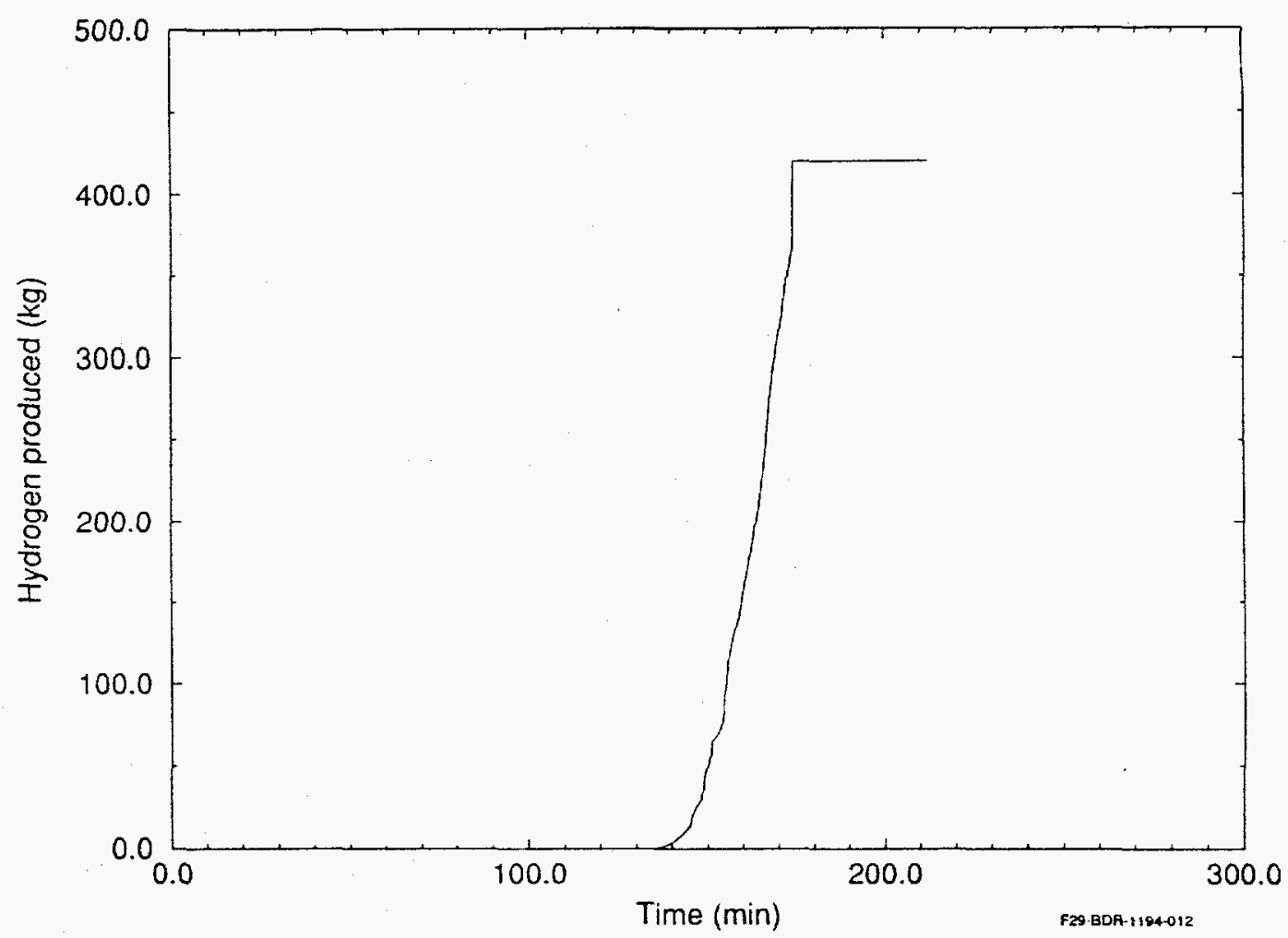

Figure 19. Predicted best-estimate integral hydrogen production. 
show the predicted best-estimate collapsed liquid level, maximum core temperature, and integral hydrogen production. As shown in Figure 19, hydrogen production is predicted to begin $135 \mathrm{~min}$ into the accident with a significant rise in production prior to the 2B pump transient. However, the total amount of hydrogen predicted during the accident is still significantly less than that estimated during the accident. The code predicted $430 \mathrm{~kg}$ hydrogen to be produced during the accident. Henrie and Postma estimated the total hydrogen production to be $460 \mathrm{~kg}^{18}$. This underprediction is consistent with other code-to-data hydrogen production comparisons of bundle reflood tests, such as CORA-13, PBF-SFD-ST, and LOFT.

It was estimated from containment radiation measurements that the fuel rod cladding began rupturing about 139 minutes into the accident. The best-estimate calculation predicted fuel rod clad ballooning and rupture to occur at 138.7 minutes. A comparison of the best-estimate and hypothesized core damage state at 173 minutes shows that the code predicted the formation of a molten pool and associated flow blockages in relatively good agreement with the hypothesized core damage state. The code also predicted partially oxidized and embrittled fuel rods in the upper core which is consistent with the formation of a loose debris bed late in the accident. Figure 20 shows the hypothesized TMI core damage state prior to the $2 \mathrm{~B}$ pump transient. The predicted core damage state is shown in Figure 21.

The 2B pump was throttled to inject $30 \mathrm{~m}^{3}$ of water. Once water started entering the core additional damage was predicted to occur. The molten pool continued heating as did some regions immediately above the pool. As material continued heating it moved downward into the pool, creating voided regions. Rubble beds continued to form above and below the molten pool as cold water contacted embrittled cladding. Small quantities of 


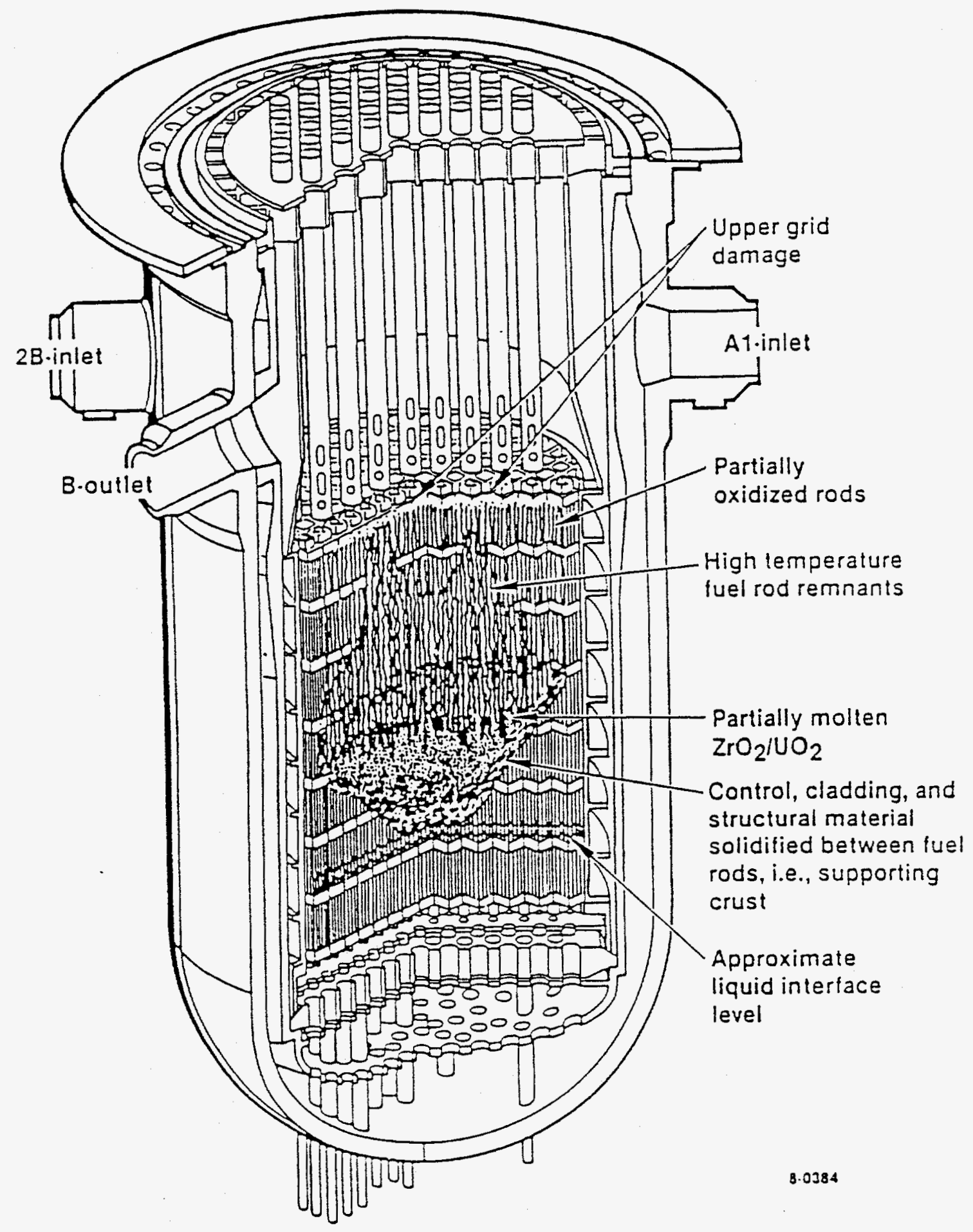

Figure 20. Hypothesized TMI-2 core damage state prior to the 2B pump transient. 


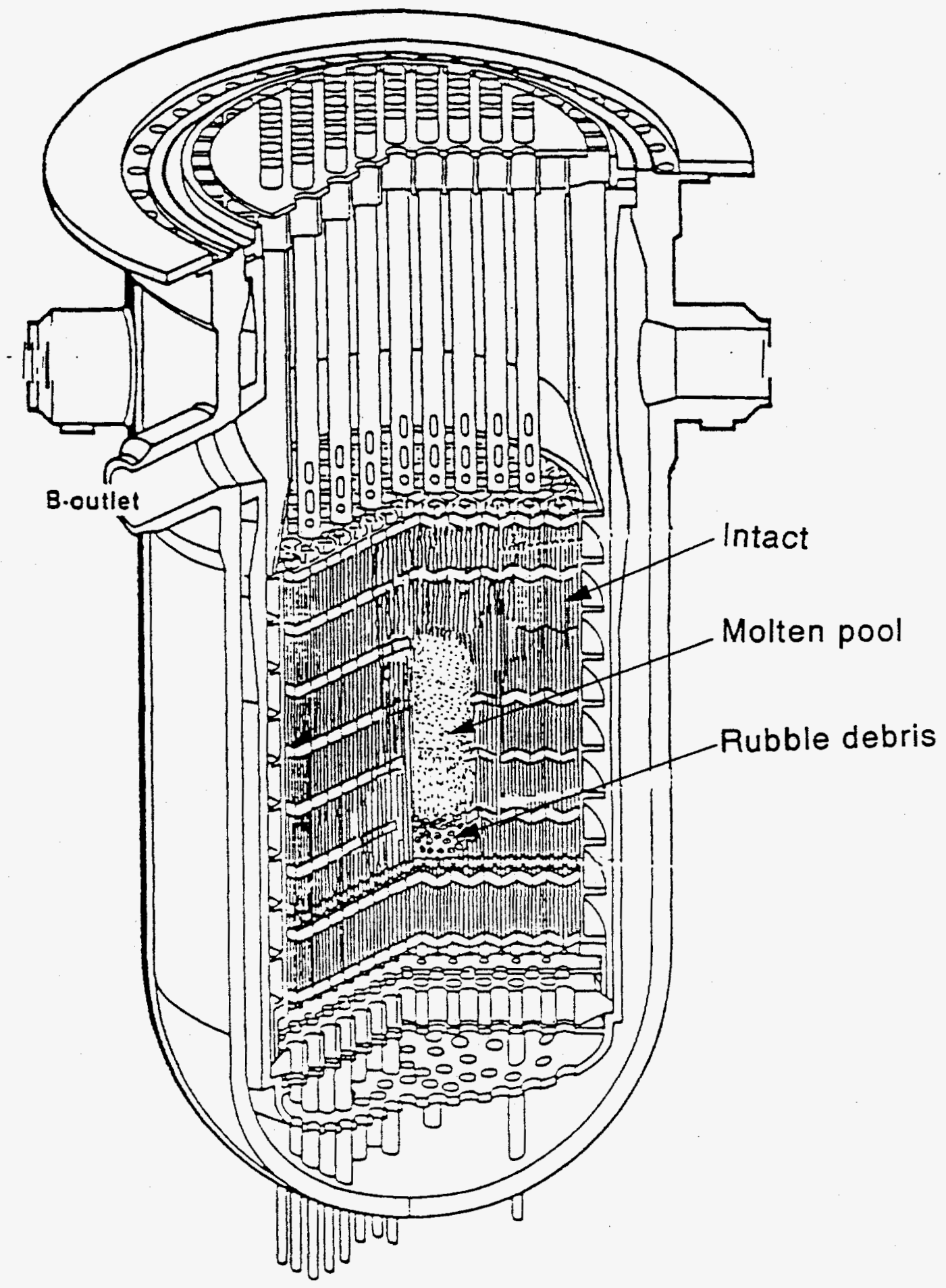

Figure 21. Predicted TMI-2 core damage state prior to the 2B pump transient. 
cohesive debris formed in the outer channels. Although rubble beds were predicted above and below the molten pool and in core region four, the pool was not calculated to slump into the lower plenum since the molten pool did not extend to the outer periphery of the core. The calculation was stopped at 226 minutes as the core appeared to have cooled considerably and the formation of additional rubble or relocation of the molten pool to the lower head did not appear imminent. The predicted end state of the reactor core had a smaller void region, and a slightly smaller molten pool. Figure 22 shows the hypothesized end-state of the core after HPI injection. The predicted endstate of the core is shown in Figure 23.

Figures 24 and 25 show the predicted radial temperature profiles of cladding temperatures at two elevations in the core region, 2.19 and $2.56 \mathrm{~m}$. Each elevation was predicted to contain molten material during the TMI-2 accident prior to the 2B-pump transient. As shown in the figures a molten pool was predicted to form in the centermost channel prior to the core reflood associated with the restart of the $2 \mathrm{~B}$-pump when the predicted temperatures reached $2873 \mathrm{~K}$. Also, the figures show channels 2 and 3 reaching temperatures in excess of the melting temperature of Zircaloy containing dissolved fuel, $2600 \mathrm{~K}$, but less than the required $2873 \mathrm{~K}$ for molten pool formation, and the two peripheral channels reaching temperatures near $2800 \mathrm{~K}$ with the production of superheated steam in conjunction with the core reflood during the 2B-pump transient.

The reflood experiments performed at the CORA, PBF, and LOFT test facilities showed metallic melts retaining coolable geometries and ceramic melts forming uncoolable molten pool regions in the core. Since SCDAP/RELAP5 models the observed experimental behavior, all core areas containing molten metallic materials are considered not completely blocked and are coolable on reflood as shown by the sharp drop in temperature to near $1200 \mathrm{~K}$ in channels 2 through 5 immediately after the restart of the 2B-pump. Temperatures in core regions containing molten 


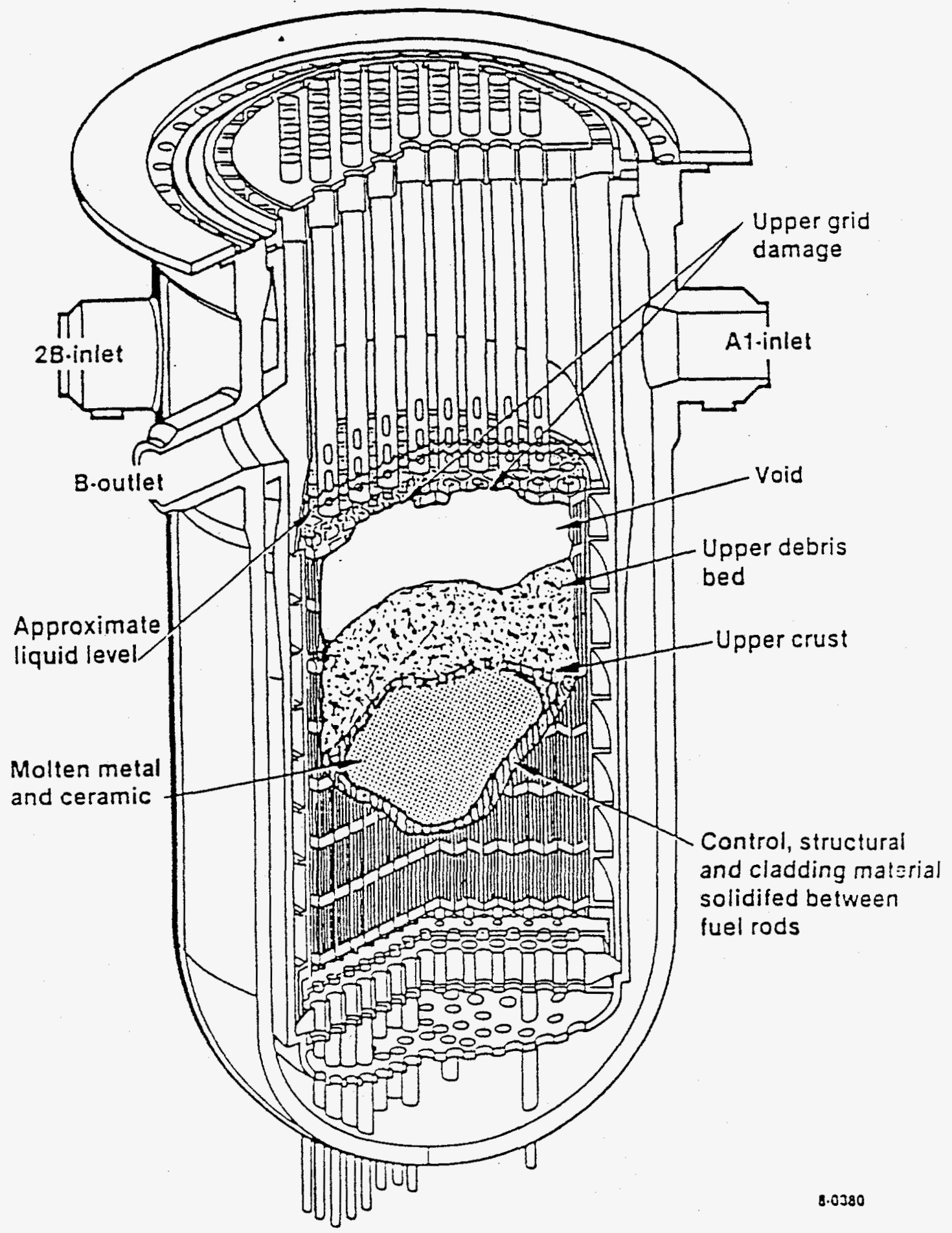

Figure 22. Hypothesized end-state of the TMI-2 core. 


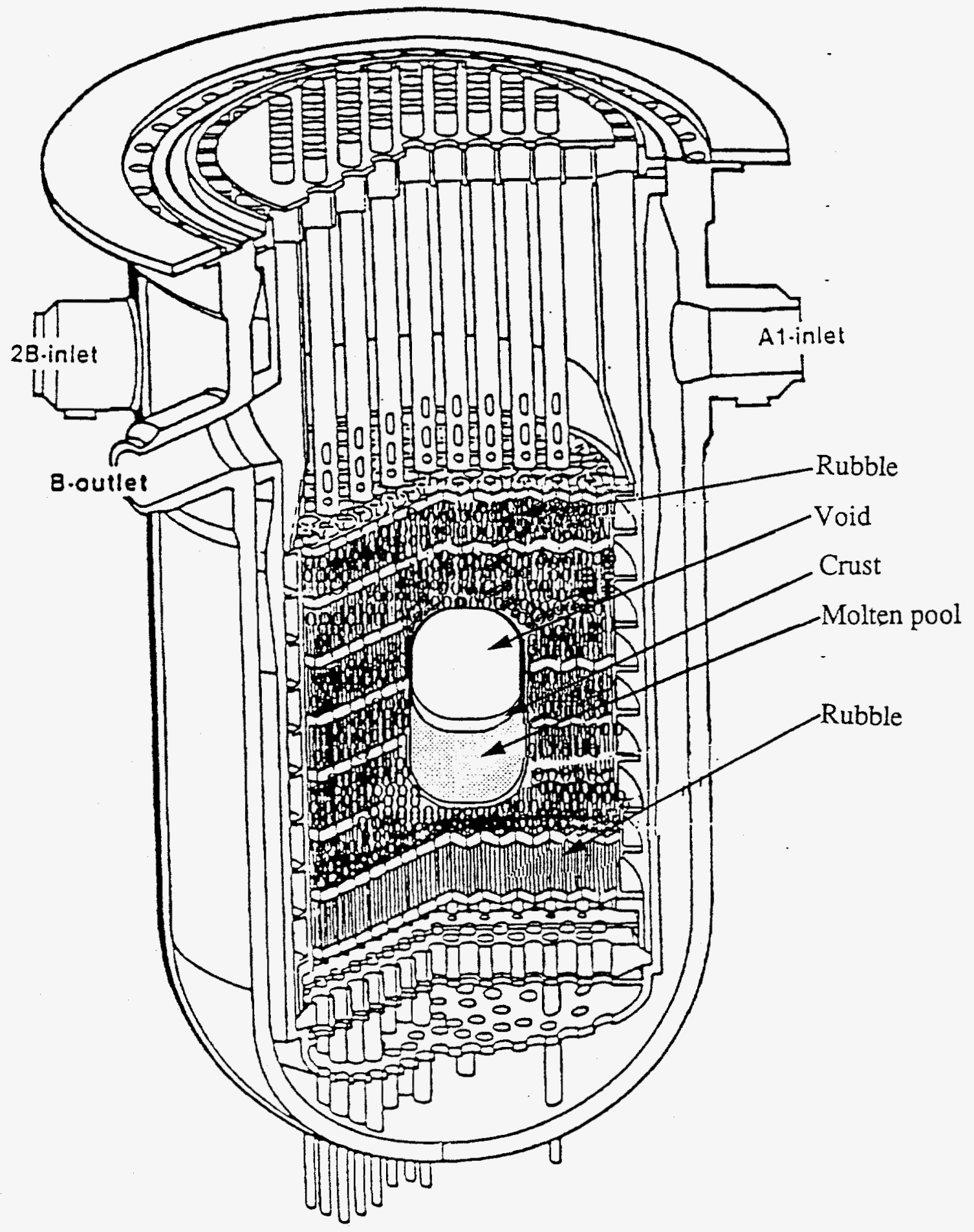

Figure 23. Predicted end-state of the TMI-2 core. 


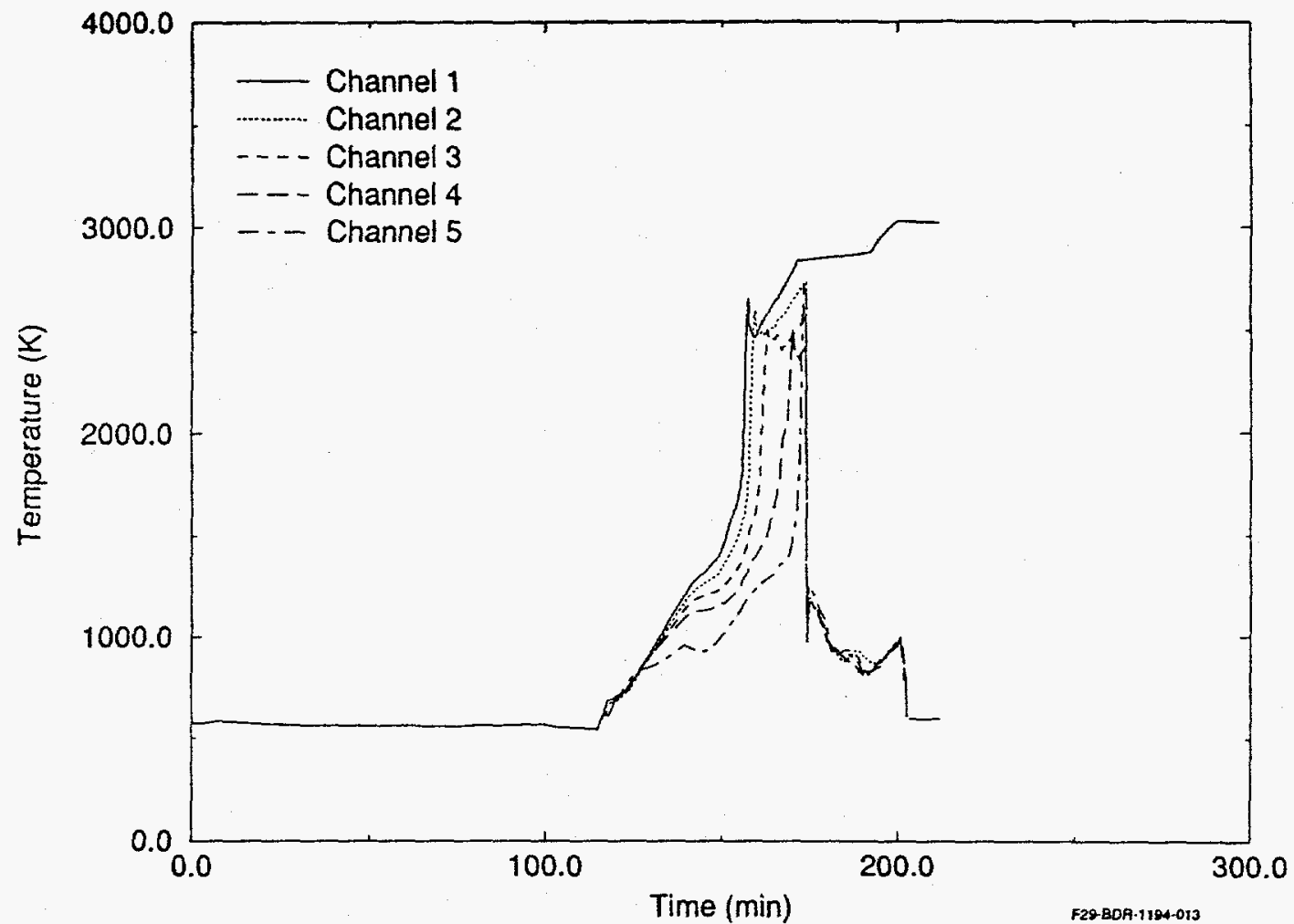

Figure 24. Predicted radial temperature profile at the $2.19 \mathrm{~m}$ elevation.

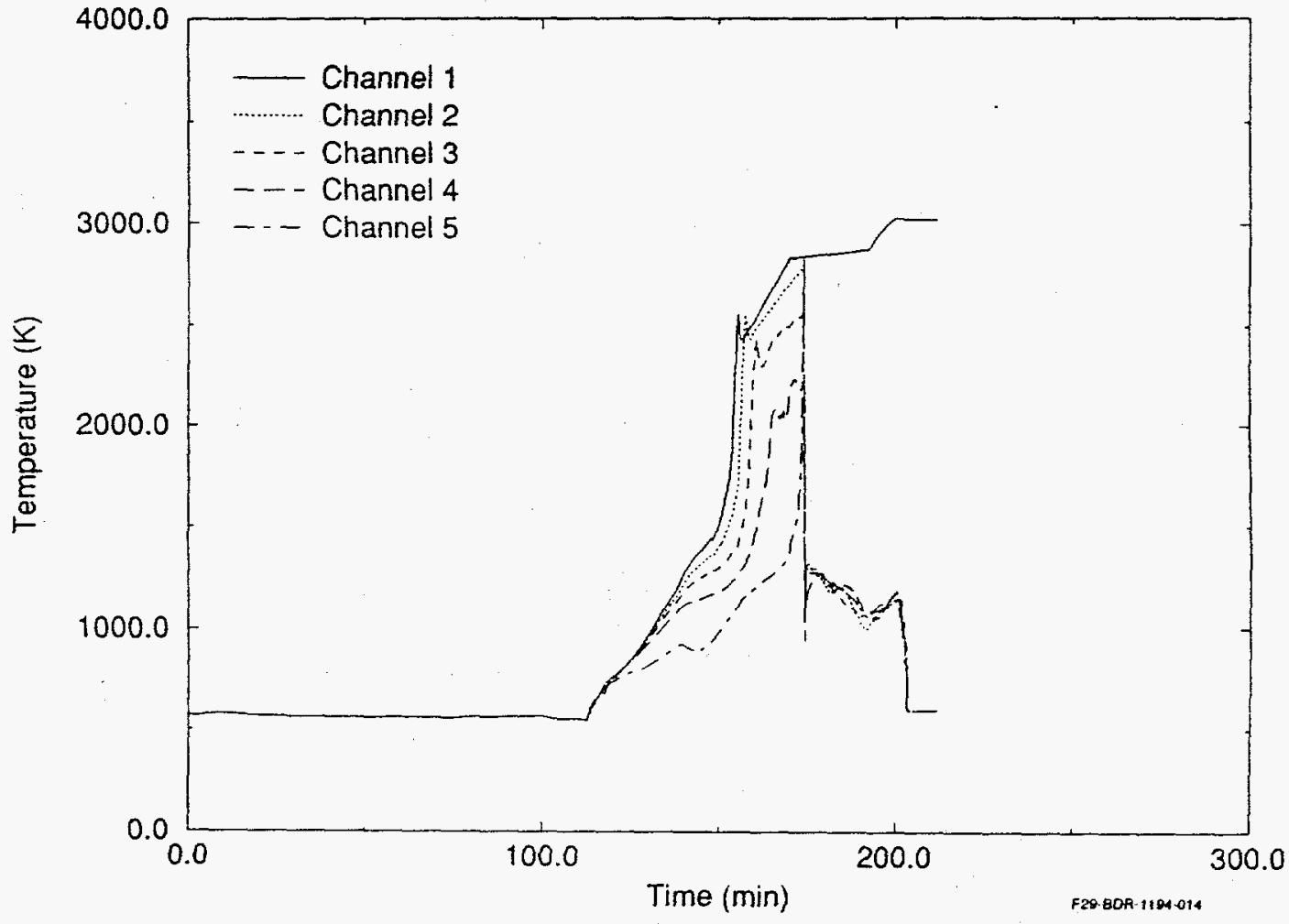

Figure 25. Predicted radial temperature profile at the $2.56 \mathrm{~m}$ elevation. 
ceramic material were predicted to remain uncoolable. As previously discussed in this section, the underprediction of pressure by the code prior to the 2B-pump transient indicates an underprediction of oxidation and hydrogen production during the core uncovery phase of the experiment in channels 2 through 5 . This underprediction results in the code predicting temperatures sufficiently high to form regions containing molten metallic core materials, but not high enough to form an uncoolable molten pool and its associated blockages. The figures also show the code predicting the melting and relocation of control and grid spacer materials between 1250 and $1500 \mathrm{~K}$ as indicated by the change in the heating rate. Molten control and grid spacer materials are predicted to relocate to the bottom of the reactor vessel and solidify in the water at the bottom of the vessel.

\subsection{Influence of Makeup Flow}

Table 6 summarizes the different makeup flow rates used for this sensitivity study. Tables 7 through 9 summarize the damage progression at three different stages of the TMI-2 accident, namely at a time prior to the $2 \mathrm{~B}$ pump transient, after the 2B pump transient, and after sustained HPI injection began. As shown in these tables, a small change in makeup flow can influence core damage dramatically. Case 1, where $4 \mathrm{~kg} / \mathrm{s}$ makeup was allowed to flow into the core from 139 to 200.2 minutes, showed the least core damage. A small fraction, 5\%, of the core was predicted to be in a damaged state prior to the $2 \mathrm{~B}$ pump transient. After the $2 \mathrm{~B}$ pump was restarted, some additional fragmentation of embrittled cladding occurred increasing the total core damage to nearly 12 percent and total hydrogen production by approximately $50 \mathrm{~kg}$ to $142 \mathrm{~kg}$. The other 5 cases showed initial core damage prior to the $2 \mathrm{~B}$ pump transient ranging from 9 to 14 percent of the core, with a molten pool size varying from 2 percent of the core, for case 2, to 14 percent for case 5 . Cases 2 and 6 showed no predicted increase in the size of the 


\begin{tabular}{clc}
\hline \multicolumn{2}{c}{ Table 6} & Summary of variation in makeup flow \\
\hline Case No. & Time(min) & Flow rates $(\mathrm{kg} / \mathrm{s})$ \\
1 & $100-139$ & 3.0 \\
& $139-200.2$ & 4.0 \\
2 & $100-139$ & 3.0 \\
& $139-200.2$ & 2.0 \\
3 & $100-139$ & 3.0 \\
& $139-200.2$ & 0.0 \\
4 & $100-122.3$ & 3.0 \\
& $122.3-200.2$ & 0.0 \\
5 & $100-116.7$ & 2.0 \\
& $116.7-125$ & 0.0 \\
& $125-174$ & 1.0 \\
& $174-200.2$ & 1.5 \\
6 & $100-116.7$ & 2.0 \\
& $116.7-125$ & 0.0 \\
& $125-200.2$ & 2.0 \\
& &
\end{tabular}

molten pool during the $2 \mathrm{~B}$ pump transient and sustained HPI injection, whereas cases 4 and 5 showed pool growth during the $2 \mathrm{~B}$ pump transient. The size of the molten pool increased slightly during the 2B pump transient for case 4 and from 13 to 16 percent of the core for case 5. All cases, except case 5, showed increased hydrogen production during the $2 \mathrm{~B}$ pump transient and no increase during sustained HPI injection. Case 5 showed increase hydrogen production during both the $2 \mathrm{~B}$ pump transient and HPI injection. During sustained HPI injection, additional fragmentation of embrittled cladding occurred. Cases 2 through 5 showed considerable differences in core damage during the sustained HPI injection phase of the accident.

Figure 26 compares the calculated system pressure for all cases with the measured system pressure, while Figures 27 through 29 show the calculated collapsed liquid level, maximum core temperature, and total hydrogen produced for each case. As shown in Figure 26, the predicted system pressure is consistently less 
than measured during core heatup and melting. Figure 27, shows the predicted collapsed liquid level for each sensitivity case. Predicted liquid level reflects the quantity water entering the core as makeup prior to the 2B pump transient. For each case, except case 1, less than $1 \mathrm{~m}$ of water was predicted to be in the

\section{rable 7. Core damage prior to the $2 B$ pump transient}

Extent of core Extent of core Hydrogen Produced

Case Number Damaged $(\%)$ Molten $(\%)$

$(\mathrm{Kg})$

1

2

3

4

5

6
5

13

12

10

14

9
0

2

7

8

9

6
93

227

321

353

300

297

Table 8. Core damage after the $2 B$ pump transient

Extent of Core Extent of Core Hydrogen Produced Case Number Damaged $\left(\frac{\%}{6}\right)$ Molten $(\%)$ (Kg)

1

2

3

4

5

6
12

21

12

11

17

12
0

2

7

8

9

6
142

240

365

395

362

348 
Table 9. Core damage after sustained HPI injection

Extent of Core Extent of Core Hydrogen Produced*

Case Number Damaged $\left(\frac{\%}{0}\right.$ Molten $\left(\frac{\xi}{2}\right)$ $(\mathrm{Kg})$

1

2

3

4

5

6
15

26

17

32

30

52
0

2

7

8

9

6
142

240

365

395

375

348

*Total estimated hydrogen production was $460 \mathrm{~kg}$.

core prior to the restart of the $2 \mathrm{~B}$ pump and to increase to slightly more than $2 \mathrm{~m}$ prior to sustained HPI injection. For all cases, water filled the core to the bottom of the hot legs after sustained HPI injection. The maximum core temperature for all cases, Figure 28, shows clearly the effect of variation in makeup flow on the formation of a molten pool. The formation of a molten pool, shown by the leveling of temperature near $2850 \mathrm{~K}$, occurs at different times during the accident for each case. Case 1 shows temperature spikes but gives no indication of a molten pool forming in the core region. As shown in Figure 29, cases 5 and 6 show similar hydrogen production behavior up to and through the $2 \mathrm{~B}$ pump transient, with case 6 predicting the production of approximately $18 \mathrm{~kg}$ more during the 2B pump transient. The code predicted an additional $45 \mathrm{~kg}$ hydrogen to be produced during sustained HPI injection for case 5 and no additional hydrogen production for case 6 . As shown in the tables, a small change in the quantity of water entering the core during the accident causes large differences in core damage, 


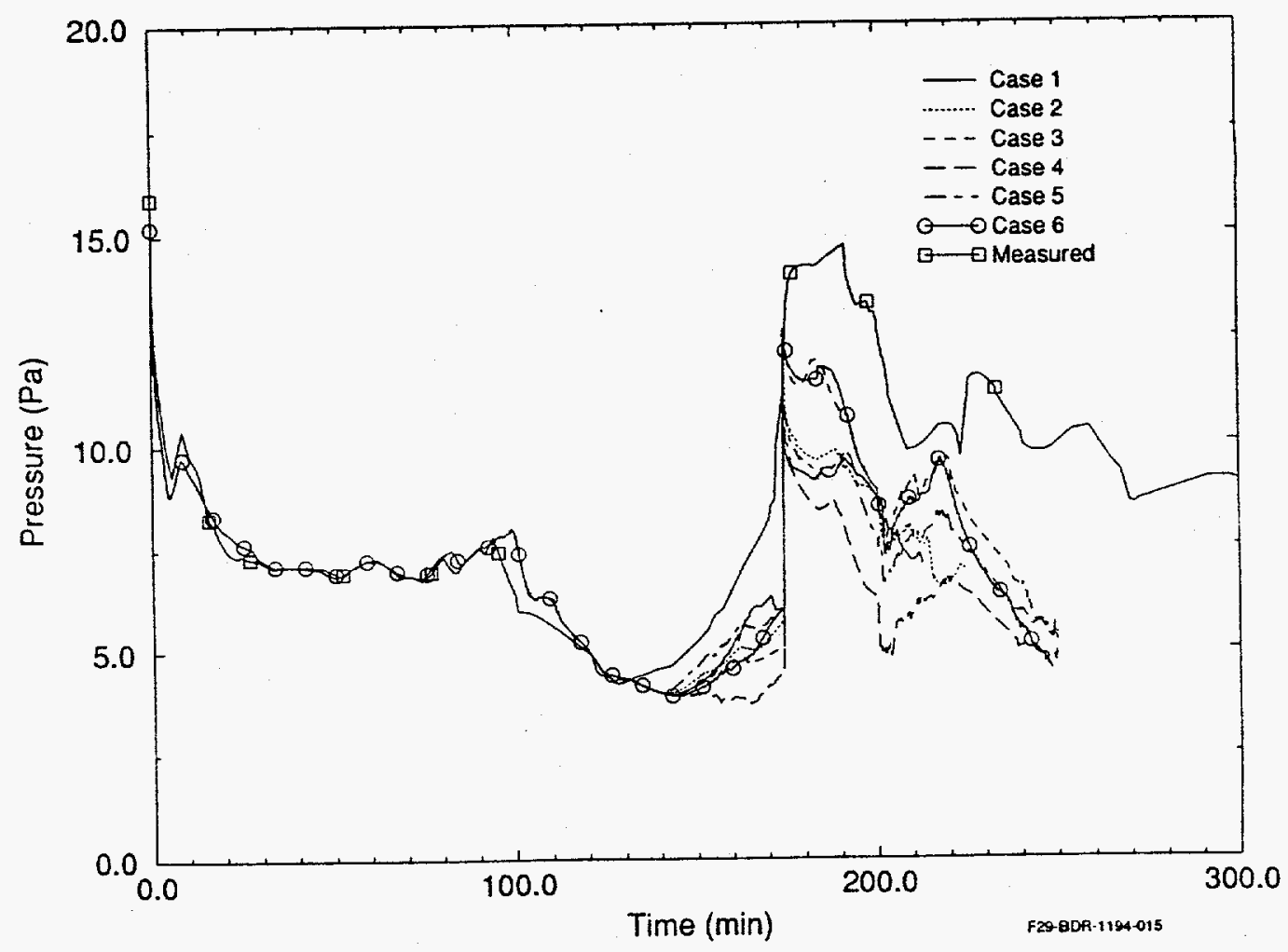

Figure 26. Calculated system pressure from sensitivity study.

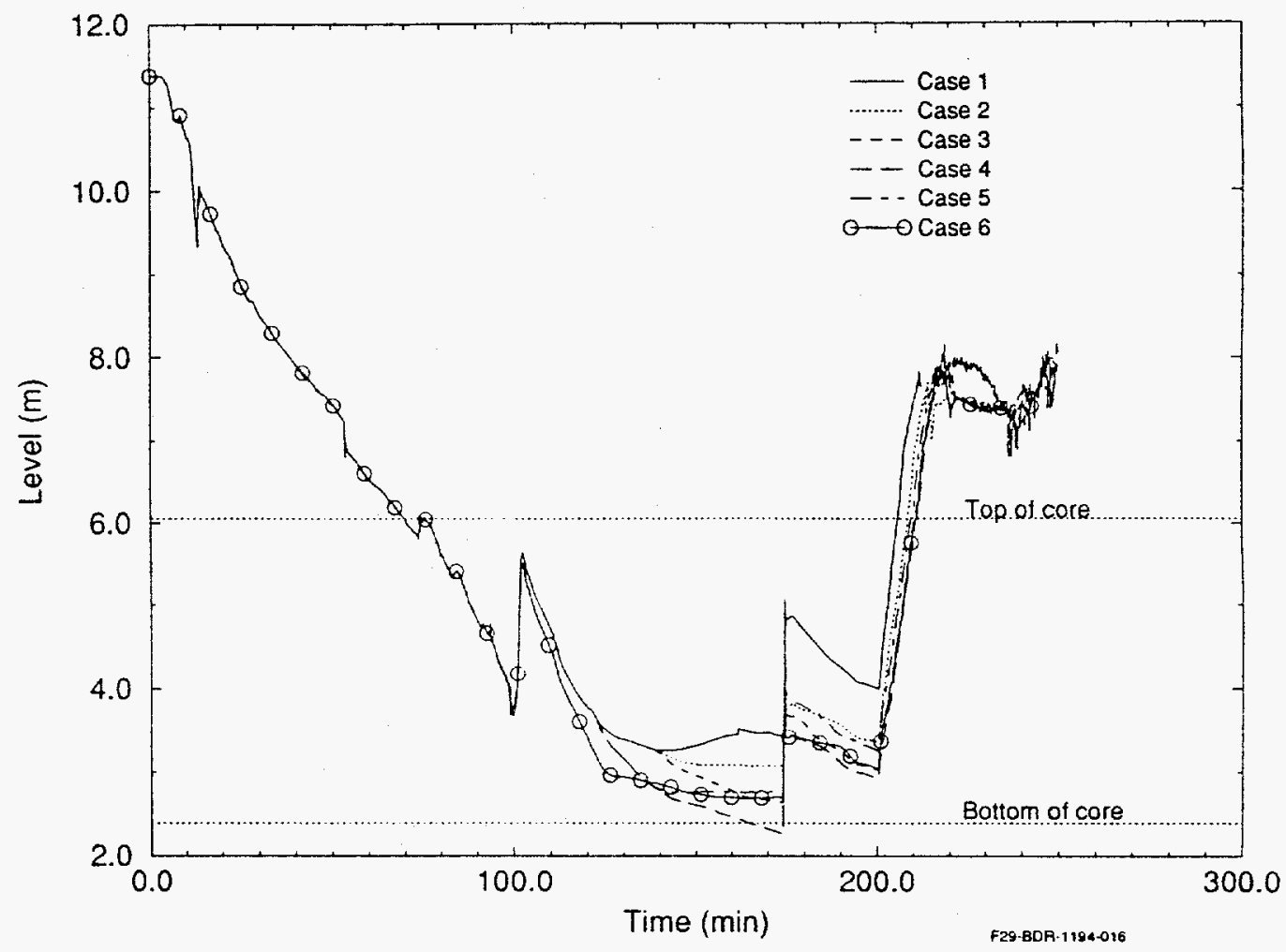

Figure 27. Calculated collapsed liquid level from sensitivity study. 


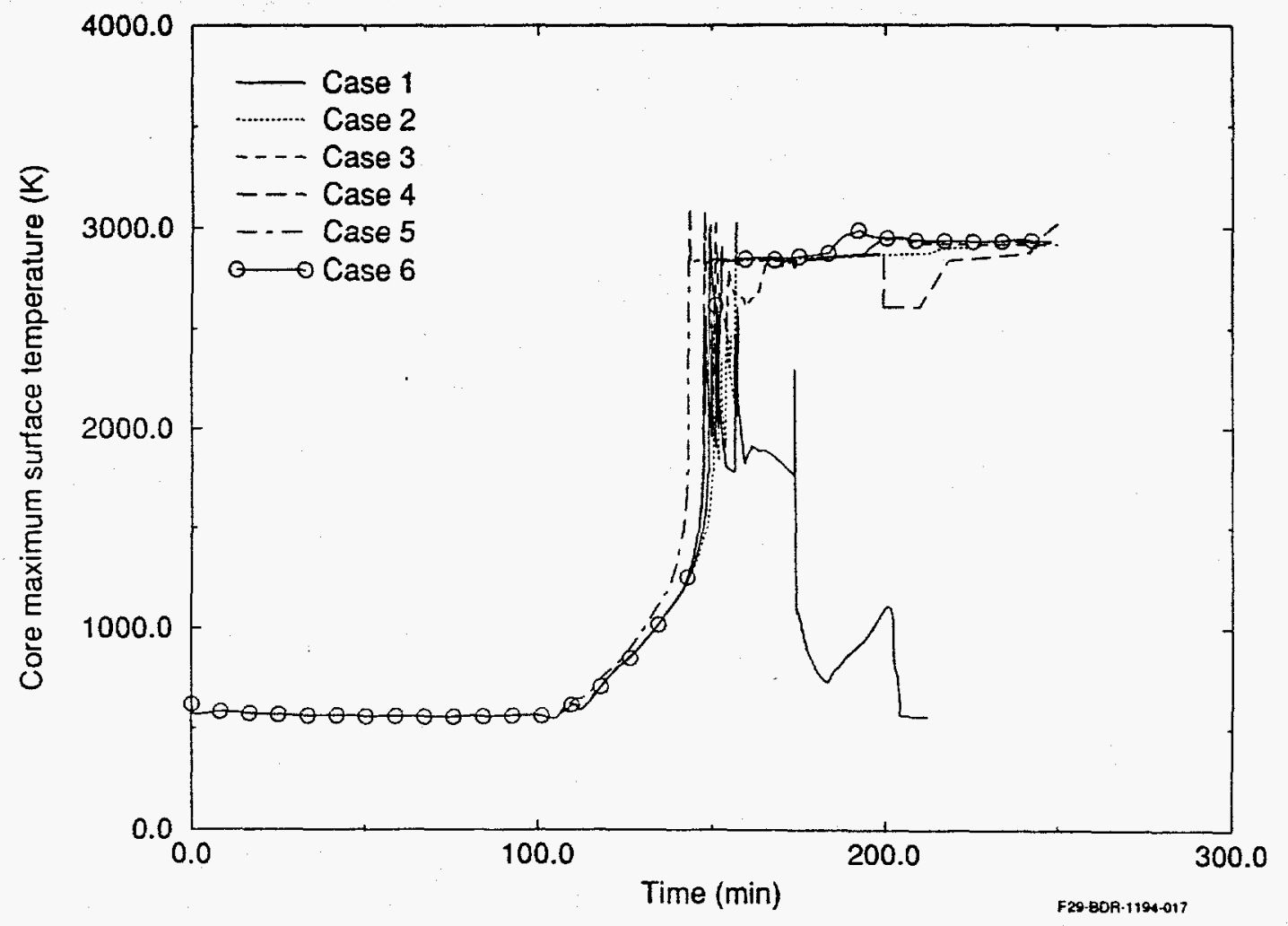

Figure 28. Calculated maximum core temperatures from sensitivity studv.

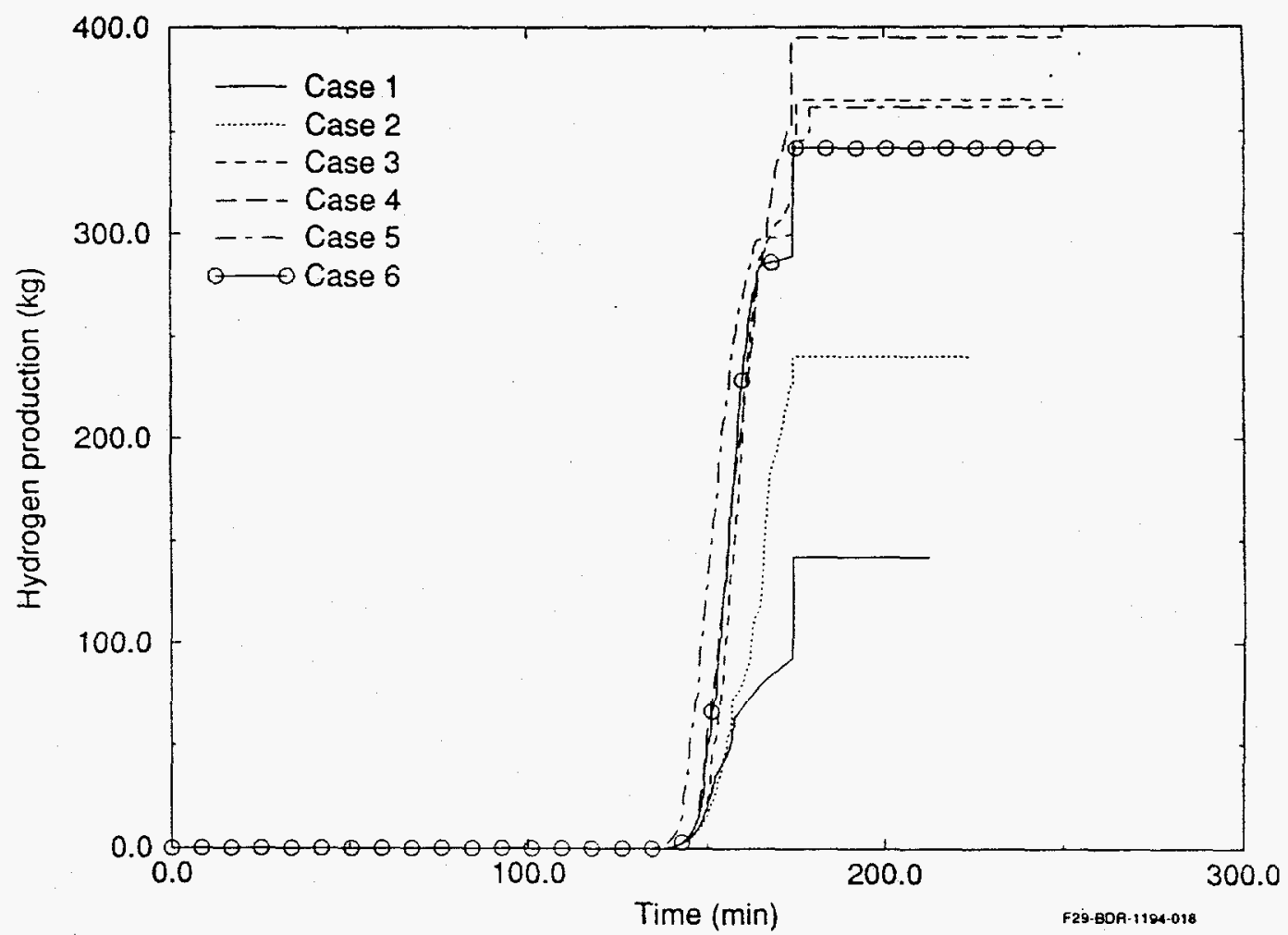

Figure 29. Integral hydrogen production from sensitivity study. 
pressure response, and predicted collapsed liquid level in the reactor vessel. Figure 30 shows the makeup flow history for the best-estimate case is considerably less than the letdown flow rate and the predicted PORV flow.

\subsection{Influence of injections during $2 B$ pump transient}

It is estimated that about thirty cubic meters of water were injected into the reactor vessel within one minute after the $2 B$ reactor coolant pump was restarted at $174 \mathrm{~min}$. How much of this water actually entered the core is unknown. The Nuclear Safety Analysis Center (NSAC) determined through analysis that 10 cubic meters of water entered the core and the remaining 20 cubic meters flowed into the bypass region ${ }^{19}$. The best-estimate calculation allowed $30 \mathrm{~m}^{3}$ of water to enter the core during the $2 B$ pump transient, which resulted in more core cooling than anticipated. A sensitivity study focusing on core damage in relation to the amount of water entering the core during the 2B pump transient was undertaken. Using the restart capability of SCDAP/RELAP5/MOD3.1, the best-estimate case was restarted just prior to the restart of the $2 \mathrm{~B}$ pump for this study. The quantity of water entering the core region and the duration of the $2 \mathrm{~B}$ pump transient were systematically varied for this study and are summarized in Table 7. The state of the core region during and after the 2B pump transient was analyzed for each case to determine the effect of changes in the quantity of reflood water entering the core on predicted damage. All cases, except case 3 , showed improved agreement with the measured pressure immediately following the $2 \mathrm{~B}$ pump transient. The pressure increase was considerably less for case 3 where 15 cubic meters of water entered the core region over a period of 40 seconds.

Case 4 predicted relocation of a small amount of molten material into the lower head as temperatures in the molten pool increased. The crust formed by rubble debris failed at the 
bottom of channel one and a finger of molten material relocated into the lower head. None of the other sensitivity cases, or the best-estimate case predicted the relocation of any molten material into the lower head.

Table 10. 2B-pump sensitivity study

Case No. Amount of Water

Duration of the Transient

Best-estimate

1

2

3

4
$30 \mathrm{~m}^{3}$

$15 \mathrm{~m}^{3}$

$30 \mathrm{~m}^{3}$

$15 \mathrm{~m}^{3}$

$22.5 \mathrm{~m}^{3}$
20 seconds

20 seconds

40 seconds

40 seconds

40 second

Pressure response during the $2 \mathrm{~B}$ pump transient was most sensitive to the amount of water entering the core region and the time the pump was allowed to run. Figure 31 compares the pressure response for the best-estimate case where thirty cubic meters of water entered the core over a period of 20 seconds to the measured and the predicted pressure response for the other cases. Predicted pressure during the $2 \mathrm{~B}$ pump transient for case 2 rose to near $14 \mathrm{MPa}$ before leveling off between 11 and $12 \mathrm{MPa}$ for over a period of 40 minutes. The predicted pressure for this case was closer to the measured pressure, though, as discussed previously, no relocation of material to the lower head occurred. As shown in the figure there is a considerable variation in pressure related to the quantity of water pumped into the core during the $2 \mathrm{~B}$-pump transient.

Other parameters such as the level of water in the core and the hydrogen production show little sensitivity to the amount of water entering the core during the $2 \mathrm{~B}$ pump transient. There are slight changes in predicted water level after the restart of the 


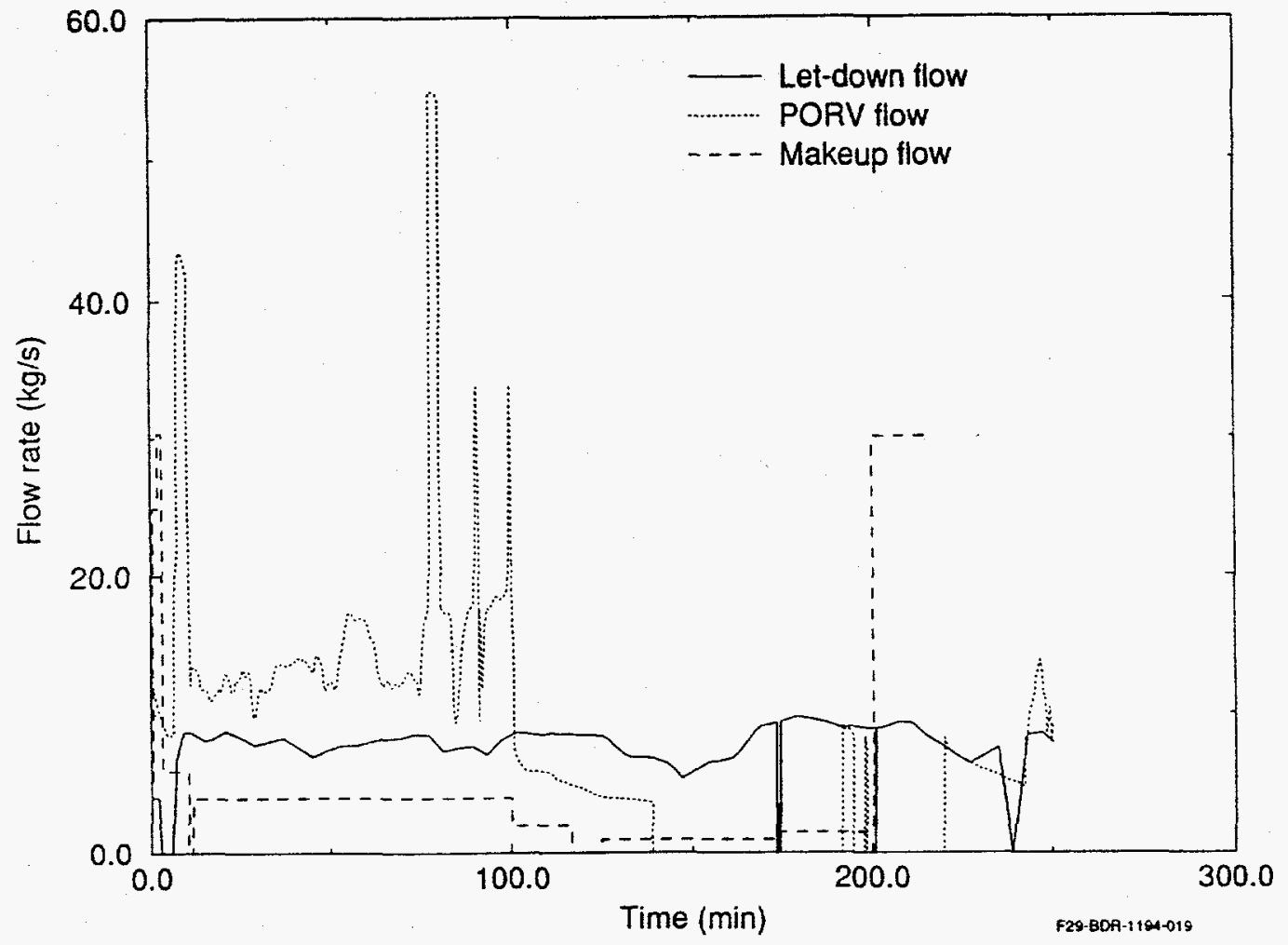

Figure 30. Makeup, letdown, and calculated PORV flows from the best-estimate case.

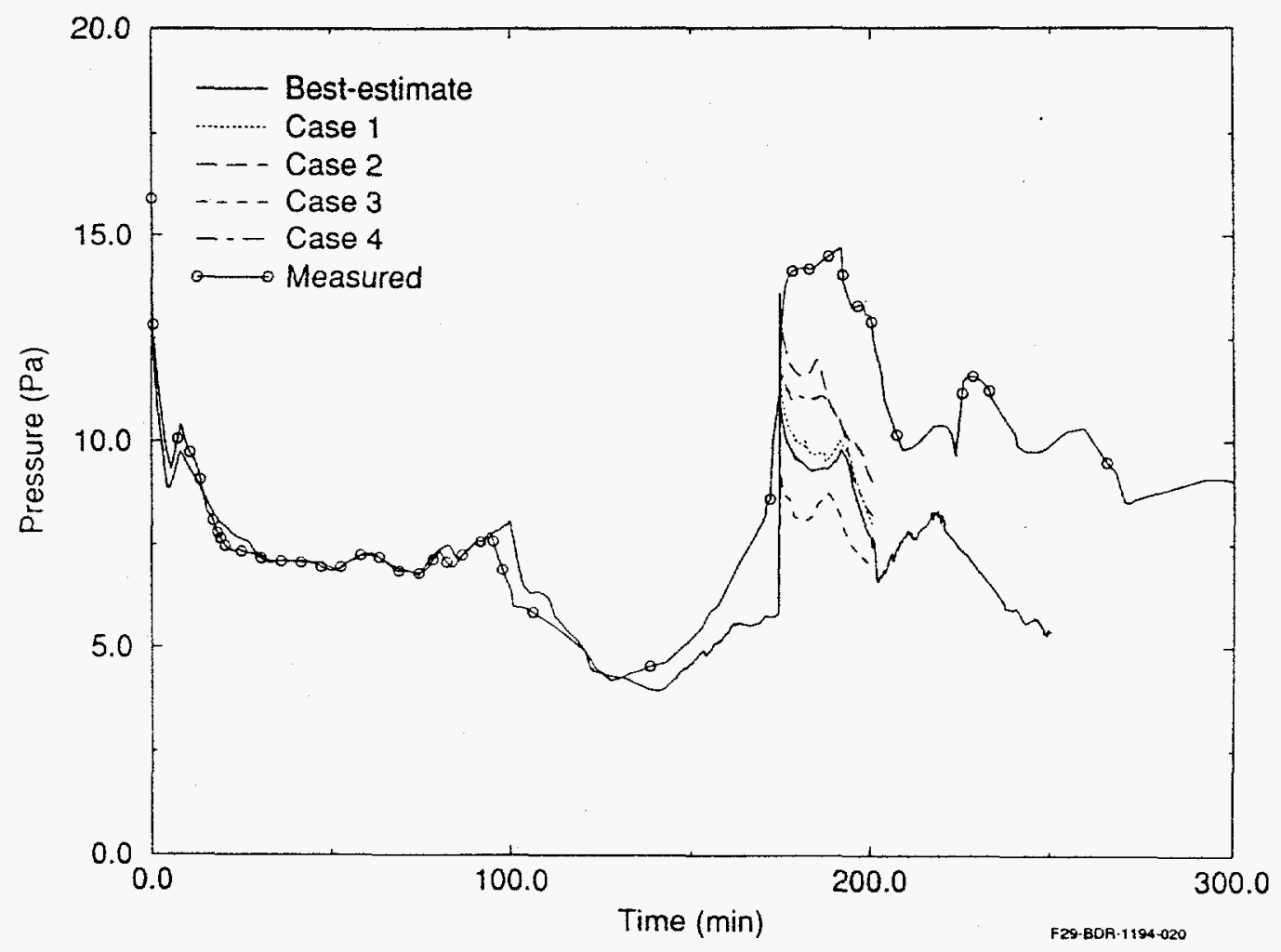

Figure 31. Calculated pressure responses from 2B pump flow sensitivity study. 
2B pump reflecting the changes in the quantity of water entering the core. There are also slight changes in the predicted quantity of hydrogen produced up to the start of sustained HPI injection.

\section{CONCLUSIONS}

SCDAP/RELAP5/MOD3. I clearly cannot predict the major events occurring in the TMI-2 accident following the 2B-pump transient. Even though the uncertainties in the system thermal hydraulics boundary conditions are very large, these uncertainties do not appear to be a significant factor in the later stages of the accident. The most obvious deficiency in the predictions following the $2 \mathrm{~B}$-pump transient is that the radial extent of the blockage and resulting molten pool is significantly underpredicted. As a consequence, the molten pool and core remains in a coolable geometry. When the core is reflooded, the molten ceramic remains within the core and eventually cools.

Although all of the factors leading to the underprediction of the radial spreading of the molten pool are not yet known, two main factors seem to be the dominant contributors;

1. The systematic underprediction of the oxidation, and resulting heat generation, during the initial melting and relocation of core material prior to and during the $2 \mathrm{~B}$-pump transient - There are two direct indications of the underprediction of the oxidation heat generation. First the total predicted hydrogen production is $90 \%$ or less than that estimated for the accident; second, the system pressure response during this period is systematically underpredicted. Although system pressure is a function of the heat removed from the system, it is also directly related to the hydrogen generation rate. The underprediction of oxidation and hydrogen production for 
this period is also consistent with the results from the MOD3.1 developmental assessment using data from reflood experiments such as CORA-13 and PBF SFD-ST.

2. The enhanced cooling of the outer assemblies during the initial heating and melting phase of the central portion of the core - Even though the outer assemblies reached temperatures near the ceramic melting point, their heating rates were slowed because of the diversion of steam from the center assemblies to the outer assemblies as damage in the centermost portions of the core grew more severe. The possible overprediction of the flow diversion associated with the initial stages of damage, such as fuel rod ballooning and the metallic melt relocation, is also consistent with the results of the MOD3.1 assessment where the flow diversion in the LOFT LP-FP-2 experiment was overpredicted. This enhanced cooling, in conjunction with the assumption that complete blockage of the outer assemblies will not occur until the ceramic melting point is reached, means that the outer assemblies did not become blocked during this period of the accident. As a result, these assemblies were relatively quickly cooled when the core was reflooded. Therefore, it was not possible for the molten pool to continue to grow out to the outer periphery of the core.

Even though MOD3.1 did not predict the relocation of melt into the lower plenum while earlier version of the code did, Mod3.1 did not predict slumping of the molten pool for the right reasons, while earlier versions predicted slumping for the wrong reasons. In earlier versions of the code, the core was predicted to block off as the result of metallic melt relocation and then the molten pool slumped because the metallic layer under the molten pool started to thin. Both of these earlier assumptions are clearly at odds with the experimental evidence that we now have. 


\section{REFERENCES}

1. SCDAP/RELAP5/MOD3.1 Code Manual Volume V: Developmental Assessment, NUREG/CR-6150, EGG-2720, to be published.

2. C. M. Allison et al., "SCDAP/RELAP5/MOD3.1 Code Development and Assessment," Proceedings of the $s$ water Reactor safety Meeting, NUREG/CP-0133, Vol. 2, April 1994.

3. D. F. Guessing, "The Three Mile Island Analysis Exercise," Nuclear Technology, 87, August 1989, pp. 298-301.

4. J. M. Broughton, P. Kuan, D. A. Petti, and E. L. Tolman, "A Scenario of the Three Mile Island Unit 2 Accident," Nuclear Technology, 87, August 1989, pp. 34-53.

5. J. R. Wolf et al., TMI-2 Vessel Investigation Project Integration Report, NUREG/CR-6197, TMI V(93) EG10, EGG-2734, March 1994.

6. C..M. Allison et al., SCDAP/RELAP5/MOD3.1 Code Manual, Volumes I-III, NUREG/CR-6150, EGG-2720, October 1993.

7. D. A. Brownson, L. N. Haney, and N. D. Chien, Intentional Depressurization Accident Management strategy for Pressurized Water Reactors, NUREG/CR-5837, EGG-2688, April 1993.

8. C. A. Dobbe, private communication, EG\&G Idaho, Inc., March 15,1994 .

9. R. W. Brower, L. J. Fackrell, D. W. Golden, M. L. Harris, and C. L. Olaveson, ICBC Version 3.1, TMI-2 Initial and Boundary Conditions Data Base, GEND-INF-078, January 1988 .

10. Y. Nomura, PORV Discharge Flow During the TMI-2 Accident, EGG-TMI-7825, July 1987.

11. D. Coleman, "As-Built Design and Material Characteristics of the TMI-2 Core," Part III in TMI-2 Accident core Heat-Up Analysis, A supplement, NSAC-25, June 1981.

12. J. I. Anderson, TMI-2 once Through Steam Generator Secondary Level Analysis, EGG-TMI-7359, January 1987.

13. P. Dumaz, "Three Mile Island Unit 2 Analysis Exercise: CATHARE Computations of Phases 1 and 2 of the Accident," Nuclear Technology, 87, December 1989, pp. 946-955. 
14. J. L. Anderson, Recommended HPI Rates for the TMI-2 Analysis Exercise (0-300 Minutes), EGG-TMI-7833, September 1987.

15. D. W. Golden and N. Ohnishi, SCDAP/RELAP5 Demonstration Calculation of the TMI-2 Accident, EGG-TMI-8473, March 1989.

16. F. E. Motley and R. P. Jenks, "Modeling of the Three Mile Island Unit 2 Accident with MELPROG/TRAC and Calculation Results for Phases 1 and 2," Nuclear Technology, 87, August 1989 , pp. 302-309.

17. T. R. England and W. B. Wilson, TMI-2 Decay Power: LASL Fission-Product and Actinide Decay Power Calculations for the President's Commission on the Accident at Three Mile Island, LA-8041-MS, Revised, March 1980.

18. J. O. Henrie and A. K. Postma, Lessons Learned from Hydrogen Generation and Buring During the TMI-2 Event, GEND-061, May 1987.

19. Staff, Nuclear Analysis Safety Center, Analysis of Three Mile Island - Unit 2 Accident, NSAC-80-1, March 1980.

20. L. J. Siefken and K. L. Davis, "Extension to the SCDAP/RELAP5 Code for the Modeling of Debris Oxidation and Material Interactions - Preliminary Design Report," EGG-RAAM-10069, February 1993.

21. Seungho Paik and L. J. Siefken, "Extension to the SCDAP/RELAP5 Code for the Modeling of Thermal-hydraulic Behavior in Porous Debris Beds - Preliminary Design Report," EGG-RAAM-10683, March 1993. 